\title{
Traditional Oriental Medicines and Alzheimer's Disease
}

\author{
Seong Gak Jeon", \#, Eun Ji Song1, \#, Dongje Lee ${ }^{1, \#, ~ J u n y o n g ~ P a r k ¹, ~ Y u n k w o n ~ N a m ², ~ J i n-i l ~ K i m ~}{ }^{3, *}$, \\ Minho Moon ${ }^{1, *}$ \\ ${ }^{1}$ Department of Biochemistry, College of Medicine, Konyang University, Daejeon 35365, Republic of Korea \\ ${ }^{2}$ Center for Organic Devices and Advanced Materials, Kyungsung University, Busan 48434, Republic of Korea \\ ${ }^{3}$ Department of Nursing, College of Nursing, Jeju National University, Jeju-si 63243, Republic of Korea
}

[Received January 16, 2018; Revised March 26, 2018; Accepted March 28, 2018]

\begin{abstract}
Alzheimer's disease (AD), which is the most major cause of dementia, is a progressive neurodegenerative disease that affects cognitive functions. Even though the prevalence of AD is continuously increasing, few drugs including cholinesterase inhibitors and $\mathrm{N}$-methyl $\mathrm{D}$-aspartate-receptor antagonists were approved to treat AD. Because the clinical trials of AD drugs with single targets, such as $\beta$-amyloid and tau, have failed, the development of multi-target drugs that ameliorate many of the symptoms of AD is needed. Thus, recent studies have investigated the effects and underlying mechanisms of herbal formulae consisting of various herb combinations used to treat AD. This review discusses the results of clinical and nonclinical studies of the therapeutic efficacy in AD and underlying mechanisms of the herbal formulae of traditional Oriental medicines and bioactive compounds of medicinal plants.
\end{abstract}

Key words: Alzheimer's disease, Oriental herbal medicine, Herbal formulae, Dementia

Alzheimer's disease (AD), the most major cause of dementia, is a progressive neurodegenerative disease involving characteristic pathologic changes, including the accumulation of $\beta$-amyloid (A $\beta)$ and neurofibrillary tangles (NFT) [1-4]. AD results in devastating healthrelated consequences, such as economic burden, decreased quality of life for the patients and their caregivers and social problems [5-7]. Because the number of AD patients continues to grow, many pharmacological and nonpharmacological interventions to improve the symptoms as well as ameliorate the pathologic changes of $\mathrm{AD}$ have been investigated. These interventions directly target acetylcholinesterase (AChE), $\mathrm{A} \beta$ peptide, or tau proteins [8-12] and/or modulate the signaling pathways underlying $\mathrm{A} \beta$ oligomer formation, tau hyperphosphorylation, or other AD-related pathologies, such as inflammation, oxidative stress and impaired adult neurogenesis [12-16]. Currently, only symptom-relieving drugs, such as AChE inhibitors (donepezil, galantamine and rivastigmine) and $\mathrm{N}$-methyl $\mathrm{D}$-aspartate (NMDA) receptor blocker (memantine), have been approved for use by the Food and Drug Administration (FDA) [17]. Moreover, despite ongoing preclinical/clinical trials, no cure for AD has been developed [4].

*Correspondence should be addressed to: Dr. Minho Moon, College of Medicine, Konyang University, Daejeon 35365, Republic of Korea. Email address: hominmoon@konyang.ac.kr; Dr. Jin-il Kim, College of Nursing, Jeju National University, Jeju-si 63243, Republic of Korea. Email address: neoreva@ hanmail.net. "\#hese authors contributed equally to this study.

Copyright: ( 2018 Jeon SJ et al. This is an open-access article distributed under the terms of the Creative Commons Attribution License, which permits unrestricted use, distribution, and reproduction in any medium, provided the original author and source are credited. 
Based on the lack of disease-modifying drugs for $\mathrm{AD}$, traditional medicines, such as natural herbal products, have been used to enhance treatment of the symptoms and pathologic processes of AD. Traditional Oriental medicines (TOMs), including herbs, from East Asian countries have long been used to treat the symptoms of dementia [18]. Recent studies have revealed that the pharmacologic compounds in TOMs have potent therapeutic effects in AD [18-20]. However, these studies have mainly focused on TOM compounds or ingredients. Indeed, the formulae of traditional medicines from East Asian countries, including China, Korea and Japan, commonly consist of multiple herbs [21]. Moreover, the formulae of traditional medicines from East Asian countries consisting of the same herbs can differ considerably [22]. Thus, the effects of mixtures of standardized formulae of TOMs need to be evaluated.

Nonetheless, few reviews have been conducted on studies of the clinical effects of TOMs on AD. Such reviews would provide a better understanding of possible strategies in the treatment of AD. Reportedly, there are abundant number of clinical or non-clinical studies revealing the beneficial effects of TOMs. In particular, reviewing TOMs prescribed for patients with cognitive impairments or aging-related symptoms in clinical settings such as Yi gan san (YGS) [23], Ba wei di huang wan (BWDHW) [24], Jiawei wen dan tang [25], Danggui shaoyao san [26], Huanglian jiedu tang (HLJDT) [27] might be more advantageous for finding potentials of TOMs on AD treatment. This review focuses on the recent findings of clinical and nonclinical studies of the mechanisms of action and therapeutic effects of five TOM formulae commonly used in the clinical treatment of patients with cognitive impairments and related symptoms.

\section{Overview of TOMs and AD}

Herbs, which have been used in Oriental medicine in East Asian countries for over 2,000 years, are currently being investigated scientifically. Treatment strategies using TOMs are of interest for many researchers because pharmacological treatments of $\mathrm{AD}$ have not yet been successful. A recent study performed a systematic literature review of 731 citations in 127 premodern Chinese medical books and identified 31 herbs used to treat memory disorders [28]. Another study reviewed the composition and underlying mechanisms of several natural active ingredients, including flavonoids, alkaloids and polysaccharides, that were isolated from Chinese herbal medicine and that have ameliorating effects on patients with $\mathrm{AD}$ [29]. An investigation of the therapeutic effects of herbal medicine and acupuncture on senile dementia found that the combined use of Chinese herbal medicine and acupuncture had potential efficacy against senile dementia [30]. Moreover, several studies have concluded that Oriental herbal medicines have positive effects on cognitive functions, including learning and memory, in patients with $\mathrm{AD}$ and vascular dementia [3133]. Recent studies focused on the effectiveness of polysaccharides derived from TOMs and single plants that traditionally used for AD-like symptoms or not for AD-like symptoms have reviewed their various effects and mechanisms [34, 35]. Moreover, one meta-analysis study has concluded that profitable effects of TOMs were not different as compared to galantamine, rivastigmine and memantine [36]. The results of these studies offer new perspectives on the therapeutic use of TOMs in the treatment of $\mathrm{AD}$.

Although few studies have reviewed the evidence for the effects of TOMs consisting of multiple herbs, combined forms of TOMs have often been prescribed and used in practice [28, 37]. Multiple lines of evidence suggest not only the effects of single herbs on AD but also the effects and underlying mechanisms of herbal formulae on AD. Thus, in this review, we discuss the effects and mechanisms of formulae used in the treatment of $\mathrm{AD}$ and suggest new perspectives of the use of alternative and complementary medicine to treat patients with AD.

\section{TOM formulae used in the treatment of $A D$ in East Asian countries}

Table 1 presents a summary of the efficacy and herb constituents of five TOM formulae used in the treatment of $\mathrm{AD}$.

\section{1) Effects of YGS on AD}

YGS (Yi gan San in Chinese, Ukgansan in Korean and Yokukansan in Japanese), which was described in a Chinese pediatric medical book (Bao ying cuo yao) published in 1,555, was originally developed to treat agitation and restlessness in children [38]. It consists of Atractylodes lancea (AL) Thunb. DC. rhizome, Wolfiporia extensa Peck Ginns sclerotium, Angelica acutiloba (AA) Siebold \& Zucc. Kitag. root, Cnidium officinale Makino rhizome, Uncaria rhynchophylla (UR) Miq. Jacks. thorn, Bupleurum falcatum (BF) L. root and Glycyrrhiza uralensis (GU) Fisch. root [39-41].

After a randomized clinical study reported attenuating effects of YGS on the behavioral and psychological symptoms of dementia (BPSD) in patients with dementia [42], preclinical and clinical trials have reported direct evidence of the positive pharmacological effects of YGS in AD. 
Table 1. Composition of five herbal formulae for the treatment of AD.

\begin{tabular}{|c|c|c|c|c|}
\hline $\mathbf{C}$ & $\mathbf{K}$ & $\mathbf{J}$ & Single herbal ingredients & Parts \\
\hline $\begin{array}{c}\tilde{\Xi} \\
\tilde{Z} \\
\tilde{\Xi} \\
\infty \\
\tilde{\beth}\end{array}$ & 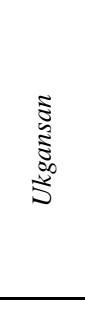 & 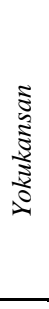 & $\begin{array}{c}\text { Atractylodes lancea Thunb. DC. } \\
\text { Wolfiporia extensa Peck Ginns*, \# } \\
\text { Angelica acutiloba Siebold \& Zucc. Kitag. } \\
\text { Cnidium officinale Makino \# } \\
\text { Uncaria rhynchophylla Miq. Jacks. } \\
\text { Bupleurum falcatum L. } \\
\text { Glycyrrhiza uralensis Fisch. } \\
\end{array}$ & $\begin{array}{l}\text { rhizome } \\
\text { sclerotium } \\
\text { root } \\
\text { rhizome } \\
\text { thorn } \\
\text { root } \\
\text { root } \\
\end{array}$ \\
\hline 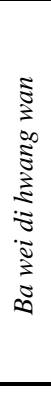 & 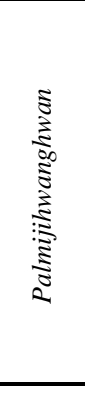 & 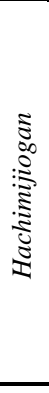 & $\begin{array}{l}\text { ehmannia glutinosa Lib. var. purpurea Makino } \\
\text { Cornus officinalis } \text { Sieb. et Zucc. } \\
\text { Dioscorea japonica Thunb. } \\
\text { Alisma orientale Sam Juzep }{ }^{* * *, \#} \\
\text { Wolfiporia extensa Peck Ginns }{ }^{*, \#} \\
\text { Paeonia suffruticosa Andrews } \\
\text { Cinnamomum cassia } \text { Blume } \\
\text { Aconitum carmichaeli } \text { Debx }{ }^{\#} \\
\end{array}$ & $\begin{array}{l}\text { root } \\
\text { fruit } \\
\text { rhizome } \\
\text { rhizome } \\
\text { sclerotium } \\
\text { cortex } \\
\text { cortex } \\
\text { root } \\
\end{array}$ \\
\hline 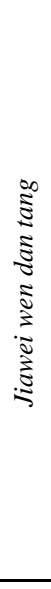 & 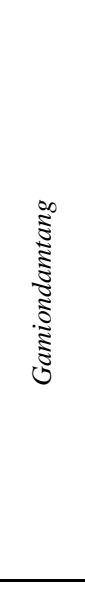 & 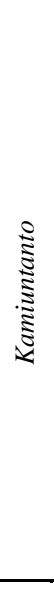 & $\begin{array}{c}\text { Pinellia ternata } \text { Breit }^{\#} \\
\text { Phyllostachys nigra Lodd. Munro } \\
\text { Wolfiporia extensa } \text { Peck Ginns*,\# } \\
\text { Citrus aurantium L.\# } \\
\text { Citrus unshiu Markov. } \\
\text { Glycyrrhiza glabra } \text { L. } \\
\text { Polygala tenuifolia Willd. } \\
\text { Scrophularia ningpoensis Hemsley } \\
\text { Panax ginseng C. A. Meyer } \\
\text { Rehmannia glutinosa } \text { Lib.* } \\
\text { Ziziphus jujuba Mill } \\
\text { Ziziphus jujuba Mill } \\
\text { Zingiber officinale Roscoe } \\
\end{array}$ & $\begin{array}{c}\text { tuber } \\
\text { stalk } \\
\text { sclerotium } \\
\text { immature fruit } \\
\text { peel } \\
\text { root } \\
\text { root } \\
\text { root } \\
\text { root } \\
\text { root } \\
\text { fruit } \\
\text { seed } \\
\text { rhizome } \\
\end{array}$ \\
\hline 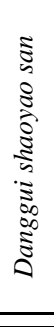 & 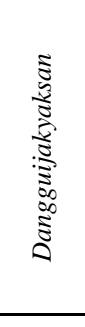 & 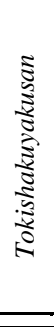 & $\begin{array}{c}\text { Angelica sinensis Oliv. Diels } \\
\text { Paeonia lactiflora Pall. } \\
\text { Ligusticum chuanxiong Hort } \\
\text { Wolfiporia extensa } \text { Peck Ginns }{ }^{*, \#} \\
\text { Atractylodes macrocephala } \text { Koidz. }{ }^{\#} \\
\text { Alisma orientalis Sam. Juzep }{ }^{* * *, \#}\end{array}$ & $\begin{array}{l}\text { root } \\
\text { root } \\
\text { rhizome } \\
\text { sclerotium } \\
\text { rhizome } \\
\text { rhizome } \\
\end{array}$ \\
\hline 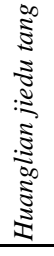 & 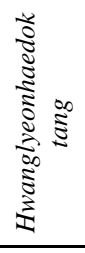 & 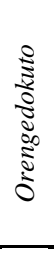 & $\begin{array}{l}\text { Coptis chinensis Franch. } \\
\text { Scutellaria baicalensis Georgi } \\
\text { Phellodendron amurense Rupr. } \\
\text { Gardenia jasminoides Ellis }\end{array}$ & $\begin{array}{l}\text { rhizome } \\
\text { root } \\
\text { cortex } \\
\text { fruit } \\
\end{array}$ \\
\hline
\end{tabular}

Duplicate herbs between formulae are indicated by the number of asterisks $\left({ }^{*}\right)$. In herbs with no direct or indirect reports regarding $\mathrm{AD}$, they are marked as hash $\left(^{\#}\right)$. (C: Chinese, K: Korean, J: Japanese) 


\section{(1) In vivo and in vitro studies of $Y G S$}

$\operatorname{Tg} 2576$ mice, an animal model of $\mathrm{AD}$, that were administered YGS showed improved performances on elevated plus-maze and Morris water-maze (MWM) tests, which suggested that YGS enhanced learning and memory functions and decreased anxiety and locomotor hyperactivity in an open-field test [43]. Interestingly, following reports of the inhibitory effects on $A \beta$ aggregation of the thorns and stems of UR, which is a YGS ingredient [44], YGS was shown to suppress $A \beta$ aggregation in vitro, while treatment with YGS or UR thorn was shown to prevent abnormal social interaction and memory disturbance in amyloid precursor protein transgenic mice [45]. However, the inhibitory effects of YGS on $A \beta$ aggregation should be further examined because conflicting results of YGS treatment ( $1.0 \%$ for 10 months) on $A \beta$ accumulation in mice have been reported [43]. One study demonstrating cholinesterase-inhibiting effects and cognitive-enhancing effects of YGS in early AD model rats has suggested the therapeutic efficacy of YGS in the treatment of the cognitive impairments of patients with AD. The cognitive-enhancing effects of YGS are mediated by increased levels of acetylcholine (ACh) and dynamin-1, a protein involved in synaptic vesicle recycling at neuronal synapses [46]. In addition to the effects of YGS on cholinergic neurotransmission, isoliquiritigenin, a component of GU root, inhibited NMDA receptors in rat cultured cortical neurons, which would ameliorate the negative effects of excessive glutamatergic transmission, a key process in cognitive dysfunction in AD [47].

Table 2. The efficacy and therapeutic mechanisms of single herbs constituting YGS on AD.

\begin{tabular}{|c|c|c|c|c|}
\hline & Single herbs & Bioactive materials & Efficacy and mechanisms & Ref. \\
\hline \multirow{19}{*}{$\begin{array}{l}n \\
0\end{array}$} & \multicolumn{2}{|c|}{ Atractylodes lancea } & Antioxidative effect & [54] \\
\hline & \multicolumn{2}{|c|}{$\beta$ 及-eudesmol } & $\begin{array}{l}\text { Inducing neurite outgrowth via MAPK activation, } \\
\text { Increasing intracellular } \mathrm{Ca}^{2+} \text { level induced by PI-PLC activation }\end{array}$ & [56] \\
\hline & \multirow{3}{*}{\multicolumn{2}{|c|}{ Angelica acutiloba }} & $\begin{array}{l}\text { Ameliorating repeated cerebral ischemia-induced memory } \\
\text { impairment }\end{array}$ & \multirow{2}{*}{ [57] } \\
\hline & & & $\begin{array}{l}\text { Increasing Ach levels and decreasing neuronal apoptosis in the } \\
\text { dorsal hippocampus }\end{array}$ & \\
\hline & & & Alleviating cognitive impairment induced by scopolamine & [58] \\
\hline & \multirow{3}{*}{\multicolumn{2}{|c|}{ Uncaria rhynchophylla }} & Inhibiting $A \beta$ aggregation & [44] \\
\hline & & & Suppressing the level of lipid peroxides & {$[59,60]$} \\
\hline & & & $\begin{array}{l}\text { Improving cognitive function and decreasing AChE activity } \\
\text { Antioxidative effect }\end{array}$ & [61] \\
\hline & & Rhynchophylline & Protecting $A \beta$-induced cytotoxicity via inhibitiion of & \\
\hline & & Isorhynchophylline & $\begin{array}{l}\text { intracellular } \mathrm{Ca}^{2+} \text { overloading } \\
\text { and tau hyperphosphorylation }\end{array}$ & [62] \\
\hline & & Geissoschizine & Non-competitive inhibition against $\mathrm{AChE}$ & [63] \\
\hline & & Uncarinic Acid C & A specific inhibitor for the $A \beta_{42}$ aggregation in nucleation phase & [64] \\
\hline & Bupleurum $f$ & lcatum & & \\
\hline & & Saikosaponin C & $\begin{array}{l}\text { Suppressing the release of } A \beta_{1-40} A \beta_{1-42} \text { in various neuronal } \\
\text { models } \\
\text { Increasing neurite outghrowth by inhibiting tau } \\
\text { hyperphosphorylation }\end{array}$ & {$[65]$} \\
\hline & Glvcurrhiza & onsis & Alleviating cognitive impairment induced by $\mathrm{A} \beta$ administration & [66] \\
\hline & огусугтиов & tatensts & Reducing activity of AChE and catalase in the brain & [00] \\
\hline & & Isoliquiritigenin & Inhibiting $A \beta$ aggregation and reducing $A \beta$ toxicity & [67] \\
\hline & Cnidium offi & inale & No direct reports regarding AD & \\
\hline & Wolfiporia e. & tensa & No direct reports regarding $\mathrm{AD}$ & \\
\hline
\end{tabular}

A $\beta$ : amyloid beta, Ach: acetylcholine, AChE: acetylcholinesterase, AD: Alzheimer's disease, Akt: protein kinase B (PKB), i.c.v: Intracerebroventricular, MAPK: mitogen-activated protein kinase, PI3K: phosphoinositide 3-kinase, PI-PLC: phosphoinositide-specific phospholipase C. 


\section{(2) Clinical trials of $Y G S$}

Randomized single-blinded clinical studies found that 4 weeks of YGS treatment ameliorated the BPSD in patients with $\mathrm{AD}$ and dementia with Lewy bodies [48] and 12 weeks of YGS treatment improved BPSD in patients with AD [49]. Additionally, a nonblinded clinical trial reported that 4 weeks of YGS administration significantly improved the BPSD in patients with AD who were being treated with regular $\mathrm{AD}$ treatments [50].

These attenuating effects of YGS on the BPSD in patients with dementia may be associated with the stimulation or inhibition of serotonergic, glutamatergic, cholinergic, dopaminergic and GABAergic neurotransmission [38]. Notably, several studies that have examined the involvement of YGS or its constituent herb in the interaction on neurotransmitter receptors involved in AD symptoms suggest that YGS may be applicable in the treatment of AD [51-53]. Thus, the results of these studies suggest that the additional use of YGS in the treatment of $\mathrm{AD}$ will be beneficial.

\section{(3) Efficacy and mechanisms of action in AD pathology of each herb in YGS}

Efficacy of single herbs of BWDHW is described on Table 2.

\section{a) AL rhizome}

AL root extract is known to be an antioxidant [54]. As the process of neurodegeneration in AD patients is influenced by increased oxidative stress [55], antioxidative features of root of AL might be involve in beneficial effects of YGS. More on antioxidative effects, $\beta$-eudesmol, one of the major constituents of the root extract of AL, induced neurite outgrowth from rat pheochromocytoma cells (PC12) cells through mitogen-activated protein kinase (MAPK) activation as well as intracellular $\mathrm{Ca}^{2+}$ level increase induced by phosphoinositide-specific phospholipase $\mathrm{C}$ activation [56].

\section{b) AA root}

Although there were no direct studies regarding $\mathrm{AD}$, one study has reported that treatment of AA root extract ameliorated repeated cerebral ischemia-induced memory impairment by increasing $\mathrm{ACh}$ levels in the dorsal hippocampus. In addition to the cognitive enhancing effects, AA root extract also prevented the neuronal apoptosis in the hippocampus [57]. Another study has shown that isolated fractions from AA root (extracted by butanol) improved scopolamine-induced memory impairment of rats [58].

\section{c) UR thorn}

UR thorn extract inhibits $A \beta$ aggregation and acts as an antioxidant by suppressing lipid peroxides [44, 59, 60]. MWM and open-field test results in a mouse model have shown that UR administration improves D-galactoseinduced cognitive impairments and decreased $\mathrm{AChE}$ activity [61]. In particular, the alkaloids rhynchophylline and isorhynchophylline isolated from UR have been shown to protect against $A \beta$-induced cytotoxicity by inhibiting intracellular $\mathrm{Ca}^{2+}$ overloading and tau protein hyperphosphorylation [62]. In addition, geissoschizine methyl ether isolated from UR exhibited reversible and noncompetitive inhibition against AChE [63], and uncarinic acid $C$ isolated from UR specifically inhibited $\mathrm{A} \beta_{42}$ aggregation in the nucleation phase [64].

\section{d) BF root}

Saikosaponin $\mathrm{C}$, one of oleanane-type triterpenes from $\mathrm{BF}$, has shown to suppress both release of $A \beta_{1-40}, A \beta_{1-42}$ in various neuronal models and increase neurite outgrowth by inhibiting abnormal tau phosphorylation in PC12 cells as well. However, activity and expression of $\beta$-site amyloid precursor protein cleaving enzyme 1 (BACE1), which is very involved in $\mathrm{A} \beta$ generation, did not changed after saikosaponin $C$ treatment [65].

\section{e) GU root}

The results of passive avoidance tests (PATs) and MWM tests have demonstrated that GU water extract administration alleviated cognitive impairments induced by $\mathrm{A} \beta$ administration in mice. In addition, $\mathrm{AChE}$ and catalase activities were significantly reduced in the brain [66]. Moreove, isoliquiritigenin, one major component of GU, not only prevents $A \beta$-aggregation but also inhibits acute $\mathrm{A} \beta$ toxicity in human $\mathrm{A} \beta$ overexpression in Caenorhabditis elegans [67].

\section{2) Effects of BWDHW on $A D$}

BWDHW (Ba wei di huang wan in Chinese, Palmijihwanghwan in Korean and Hachimijiogan in Japanese), is composed of the following eight herbs: Rehmannia glutinosa (RG) Libosch. var. purpurea Makino root, Cornus officinalis (COF) Sieb. et Zucc. fruit, Dioscorea japonica (DJ) Thunb. rhizome, Alisma orientale Sam Juzep. rhizome, Wolfiporia extensa Peck Ginns sclerotium, Paeonia suffruticosa (PS) Andrews cortex, Cinnamomum cassia (CC) Blume cortex and Aconitum carmichaeli Debx root [68]. 
Table 3. The efficacy and therapeutic mechanisms of single herbs constituting BWDHW on AD.

\begin{tabular}{|c|c|c|c|c|}
\hline & Single herbs & Bioactive materials & Efficacy and mechanisms & Ref. \\
\hline \multirow{20}{*}{$\begin{array}{l}3 \\
1 \\
0 \\
0\end{array}$} & \multirow{2}{*}{\multicolumn{2}{|c|}{ Rehmannia glutinosa }} & $\begin{array}{l}\text { Improving scopolamine-induced cognitive impairment and cholinergic } \\
\text { dysfunctions with decreasing TNF- } \alpha \text { and IL- } 1 \beta \text { mRNA expression }\end{array}$ & {$[75]$} \\
\hline & & & $\begin{array}{l}\text { Increasing the gene expression of GDNF in astroglial cells via } \\
\text { ERK1/2 and cPKC }\end{array}$ & {$[76]$} \\
\hline & & \multirow[b]{2}{*}{ Catalpol } & Increasing ChAT and BDNF levels & [73] \\
\hline & & & $\begin{array}{l}\text { Improvement of } A \beta \text {-induced memory and learning impariment via } \\
\text { reducing } A \beta \text { and regulating ROS related enzymes }\end{array}$ & {$[74]$} \\
\hline & Cornus officin & & & \\
\hline & & Loganin & $\begin{array}{l}\text { Improving scopolamine-induced memory impairment and } \\
\text { significantly inhibit AChE activity }\end{array}$ & {$[77]$} \\
\hline & & p-Coumaric acid & $\begin{array}{l}\text { Inhibiting BACE1 via bind to the } \beta \text {-secretase subsite or to another } \\
\text { regulatory site }\end{array}$ & \multirow{3}{*}[78]{} \\
\hline & & Gallic acid & \multirow{2}{*}{ Inhibiting BACE1 activity } & \\
\hline & & Ursolic acid & & \\
\hline & & $\begin{array}{l}\text { 1,2,3,6-tetra-O- } \\
\text { galloyl- } \beta \text {-D-glucose }\end{array}$ & $\begin{array}{l}\text { Inhibiting BACE1 via interaction with both the peripheral anionic } \\
\text { sites and the catalytic active sites }\end{array}$ & \multirow{2}{*}{ [79] } \\
\hline & & Tellimagrandin II & $\begin{array}{l}\text { Inhibiting ChEs via interaction with both the peripheral anionic sites } \\
\text { and the catalytic active sites }\end{array}$ & \\
\hline & \multicolumn{2}{|c|}{ Dioscorea japonica } & & \\
\hline & & Coreajaponin B & Upregulating NGF without cell toxicity & {$[80]$} \\
\hline & \multicolumn{2}{|c|}{ Paeonia suffruticosa } & & \\
\hline & & $\begin{array}{l}1,2,3,4,6-\text { penta-O- } \\
\text { galloyl- } \beta \text {-D- } \\
\text { glucopyranose }\end{array}$ & $\begin{array}{l}\text { Inhibiting the } A \beta \text {-aggregation, destabilizing the pre-formed } A \beta \text { fibrils } \\
\text { Alleviating long-term memory impairment in } \operatorname{Tg} 2576 \text { mice }\end{array}$ & [81] \\
\hline & & Paeonol & $\begin{array}{l}\text { Improving the impaired learning behavior induced by } A \beta \text { intra- } \\
\text { hippocampal injection } \\
\text { Suppressing apoptosis via upregulation of cytochrome oxidase and } \alpha \text { - } \\
\text { actin }\end{array}$ & {$[82]$} \\
\hline & \multicolumn{2}{|c|}{ Cinnamomum cassia } & $\begin{array}{l}\text { Improvement of cognitive function and glucose homeostasis damaged } \\
\text { by A } \beta \text { accumulation via enhancing insulin signaling and suppressing } \\
\text { TNF- } \alpha \text { and iNOS }\end{array}$ & {$[83]$} \\
\hline & \multicolumn{2}{|c|}{ Alisma orientale } & No direct reports regarding $\mathrm{AD}$ & \\
\hline & \multicolumn{2}{|c|}{ Aconitum carmichaeli } & No direct reports regarding $\mathrm{AD}$ & \\
\hline & \multicolumn{2}{|c|}{ Wolfiporia extensa } & No direct reports regarding $\mathrm{AD}$ & \\
\hline
\end{tabular}

A $\beta$ : amyloid beta, AChE: acetylcholinesterase, AD: Alzheimer's disease, BACE1: beta- site amyloid precursor protein cleaving enzyme 1, BDNF: brainderived neurotrophic factor, ChAT: choline acetyltransferase, ChEs: cholinesterases, cPKC: conventional protein kinase C, ERK1/2: extracellular signalregulated kinases. 1/2, GDNF: glial cell line-derived neurotrophic factor, IL-1 $\beta$ : interleukin 1 beta, iNOS: inducible nitric oxide synthase, NGF: nerve growth factor, ROS: reactive oxygen species, Tg2576: mouse model of AD with APP Swedish mutation (KM670/671NL), TNF- $\alpha$ : tumor necrosis factor alpha.

\section{a) In vivo and in vitro studies of $B W D H W$}

BWDHW treatment ( $100 \mu \mathrm{g}$ for 7 days) stimulated neurite outgrowth from PC12m3 cells under NGF [69]. In addition, the results of animal experiments provide more evidence for the effects of BWDHW on cognitive function. In rats with scopolamine-induced memory disturbance, the administration of BWDHW significantly increased the number of correct choices and decreased the number of error choices made in a radial maze test [70]. Moreover, BWDHW $(0.5 \mathrm{~g} / \mathrm{kg})$ administration prolonged the step-through latencies that were shortened in the PAT after amnesia was induced by scopolamine, cycloheximide and cerebral ischemia [71]. In addition,
BWDHW increased the levels of $\mathrm{ACh}$, choline acetyltransferase (ChAT) activity in the frontal cortex of normal rats [70]. Thus, the underlying mechanisms of the cognitive-enhancing effects of BWDHW are, in part, associated with effects that preserve ACh content and modulate AChE and ChAT activity. Because most FDAapproved drugs for AD are AChE inhibitors, BWDHW might serve as a therapeutic agent in the treatment of cognitive dysfunction in AD.

\section{b) Clinical trials of $B W D H W$}

A randomized clinical trial has shown that BWDHW treatment is beneficial in elderly patients with mild to severe dementia. An experimental group treated with $2 \mathrm{~g}$ 
of BWDHW 3 times a day for 8 weeks showed significantly increased scores on the Mini-Mental State Examination (MMSE) and Barthel Index [24]. In addition, patients with multiple cerebral infarctions treated with BWDHW for 8 weeks exhibited improved cognitive function and significantly increased cerebral blood flow $(\mathrm{CBF})$ in the whole brain and multiple regions (temporal lobe, Broca's area and thalamus) [72]. Although these studies examined patients with various types of dementia, the results suggest possible benefits of the use of BWDHW in AD.

\section{(1) Efficacy and mechanisms of action in AD pathology of each herb in BWDHW}

Efficacy of single herbs of BWDHW is described on Table 3.

\section{a) $R G$ root}

Direct evidence on the efficacy of $R G$ root in $A D$ treatment has not been reported. However, RG-derived catalpol, an iridoid glycoside from RG, improved the learning and memory impairments exhibited in $A \beta-$ induced neurodegenerative mouse models by decreasing $\mathrm{A} \beta$, regulating radical oxygen species-related enzymes and increasing brain-derived neurotrophic factor (BDNF) level [73, 74]. In addition, MWM test and PATs results have demonstrated that the administration of steamed RG root improved scopolamine-induced cognitive dysfunction and cholinergic immunoreactivity impairments through the decreased expression of tumor necrosis factor- $\alpha$ (TNF- $\alpha$ ) and interleukin-1 $\beta$ (IL-1 $\beta$ ) mRNA [75]. Moreover, RG increased the gene expression of glial cell line-derived neurotrophic factor (GDNF) in astroglial cells through phosphorylation of extracellular signal-regulated kinase 1/2 (ERK1/2) independently of cyclic adenosine monophosphate (cAMP)-dependent protein kinase $\mathrm{C}$ pathways [76].

\section{b) COF fruit}

The methanolic extract of COF and its major component, loganin, have been reported to improve scopolamineinduced memory impairments and significantly inhibit $\mathrm{AChE}$ activity in mice [77]. In addition, p-coumaric acid, gallic acid and ursolic acid derived from the ethyl acetate fraction of COF inhibited BACE1 activity. In particular, p-coumaric acid showed to inhibit BACE1 activity dosedependently via binding to the $\beta$-secretase subsite or to another regulatory site [78]. Moreover, tellimagrandin II and 1,2,3,6-tetra-O-galloyl-b-D-glucose, the constituents of COF, showed inhibiting effects on AChE and BACE1 respectively via interaction with both the peripheral anionic sites and the catalytic active sites of each enzyme [79].

\section{c) DJ rhizome}

Direct evidence for the efficacy of the DJ rhizome in AD treatment has not been reported. However, coreajaponin $\mathrm{B}$, which is obtained by purifying a DJ extract from $50 \%$ aqueous alcohol through multiple chromatographic steps, has shown to up-regulate nerve growth factor (NGF) without cell toxicity in a C6 rat glioma cell line [80].

\section{d) PS cortex}

PS cortex and its active ingredient 1,2,3,4,6-penta-Ogalloyl- $\beta$-D-glucopyranose has been shown to inhibit $A \beta_{1-}$ $40,1-42$ fibril formation, diminish pre-formed $A \beta$ fibrils and alleviate long-term memory impairments in $\mathrm{Tg} 2576$ mice as well [81]. In addition, paeonol (2'-hydroxy-4'methoxyacetophenone;1-(2-hydroxy-4-

methoxyphenyl)ethan-1-one), one of the active ingredients of PS, improved learning behavior impairments induced by $A \beta_{1-42}$ intrahippocampal injections in rat models via the suppression of apoptosis with elevated levels of cytochrome oxidase 1 in the hippocampus, cortex and vascular $\alpha$-actin [82].

\section{e) CC cortex}

$\mathrm{CC}$ cortex has been shown to improve cognitive function and glucose homeostasis damaged by hippocampal CA1 infusion of $A \beta_{25-35}$ in rats via reducing $A \beta$ deposition, enhancing insulin signaling and suppressing inflammatory mediator such as TNF- $\alpha$ and inducible nitric oxide synthase (iNOS) [83].

\section{3) Effects of JWWDT on AD}

JWWDT (Jiawei wen dan tang in Chinese, Gamiondamtang in Korean and Kamiuntanto in Japanese) is traditionally used to treat neurosis and insomnia [84, 85]. JWWDT consists of the following 13 herbs: Pinellia ternata Breit. tuber, Phyllostachys nigra (PN) Lodd. Munro stalk, Wolfiporia extensa Peck Ginns sclerotium, Citrus aurantium L. immature fruit, Citrus unshiu (CU) Markov. peel, Glycyrrhiza glabra (GG) L. root, Polygala tenuifolia (PT) Willd. root, Scrophularia ningpoensis (SN) Hemsley root, Panax ginseng (PG) C.A. Meyer root, RG root, Ziziphus jujuba (ZJ) Mill. fruit, ZJ seed and Zingiber officinale (ZO) Roscoe rhizome [84]. JWWDT has been reported to improve the cognitive symptoms of AD. 
Table 4. The efficacy and therapeutic mechanisms of single herbs constituting JWWDT on AD.

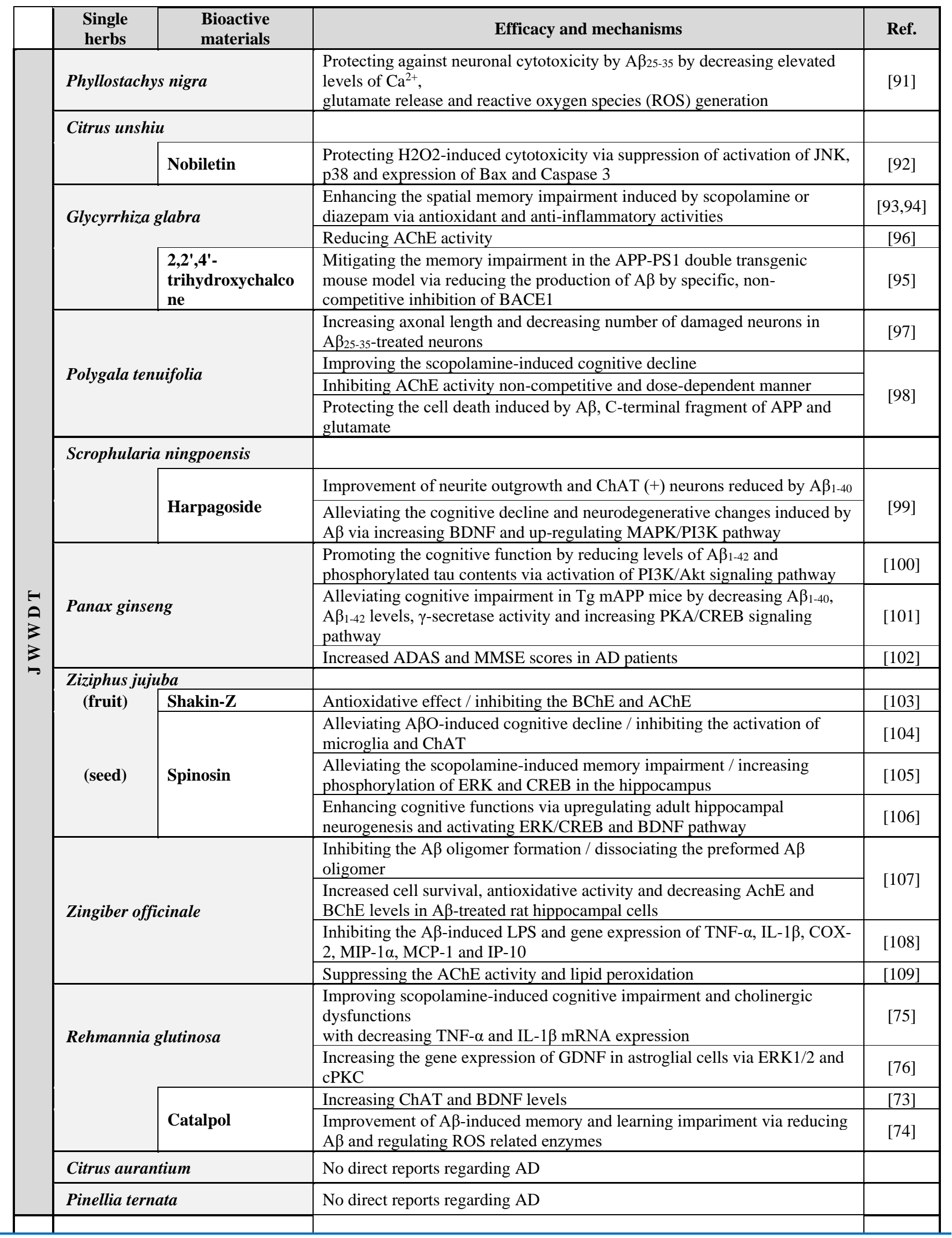




\section{\begin{tabular}{l|l} 
Wolfiporia extensa & No direct reports regarding AD
\end{tabular}}

A $\beta$ : amyloid beta, A $\beta O$ : amyloid beta oligomers, AChE: acetylcholinesterase, AD: Alzheimer's disease, ADAS: Alzheimer's disease assessment scale, Akt: protein kinase B (PKB), APP: amyloid precursor protein, BACE1: beta-site amyloid precursor protein cleaving enzyme 1, BChE: butyrylcholinesterase, BDNF: brain-derived neurotrophic factor, ChAT: choline acetyltransferase, COX-2: cyclooxygenase-2, cPKC: conventional protein kinase C, CREB: cAMP responsive element binding protein, ERK: extracellular signal-regulated kinases, GDNF: glial cell line-derived

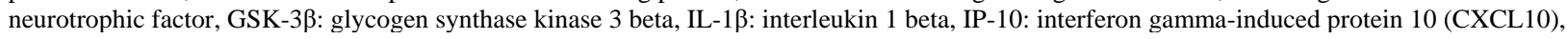
MAPK: mitogen-activated protein kinase, MCP-1: monocyte chemotactic protein 1(CCL2), MIP-1 $\alpha$ : macrophage inflammatory protein 1-alpha (CCL3), MMSE: mini-mental state examination, PI3K: phosphoinositide 3-kinase, PS1: presenilin 1, PKA: protein kinase A, p-tau: phosphorylated tau, ROS: reactive oxygen species, TNF- $\alpha$ : tumor necrosis factor alpha.

\section{a) In vivo and in vitro studies of JWWDT}

The results of several in vivo and in vitro experiments suggest potential benefits of the use of JWWDT in the treatment of AD. Yabe, et al. [86] have demonstrated that the oral administration of JWWDT improves age-related memory disturbances in rats by increasing ChAT and NGF levels in the basal forebrain and frontoparietal cortex, respectively. Subsequently, Yabe, et al. (87) revealed that Polygalae Radix (PT root), a constituent of JWWDT, is involved in increasing the levels of ChAT activity in the basal forebrain and NGF secretion in astroglial cells. Similar to these results, an in vitro study of cultured basal forebrain and cerebral cortex cells from rat embryos has indicated that JWWDT treatment increases the levels of ChAT and NGF mRNA, respectively [88]. An animal study of the oral administration of JWWDT to mice with memory impairments induced by a thiamine-deficient diet has shown that JWWDT prolonged the shortened latency times in the PAT and shortened the transfer latency during the retention trial in the elevated plus-maze test, which indicated that learning and memory were improved. In addition to these behavioral assessments, immunohistochemical assays have shown that JWWDT attenuates the decrements in ChAT activity in the hippocampus [84]. Moreover, the results of these in vivo and in vitro animal studies support the results of clinical trials reporting cognitive-enhancing effects of JWWDT.

\section{b) Clinical trials of JWWDT}

Arai, et al. [89] have shown that the oral administration of JWWDT delayed the rate of cognitive decline on the MMSE of patients but did not change the amounts of $A \beta_{1-}$ 42 and tau proteins in cerebrospinal fluids of AD patients. In another clinical study, the combined use of JWWDT and donepezil resulted in better clinical outcomes, including improved MMSE scores, Alzheimer's disease assessment scale (ADAS)-cognitive subscale scores, and improved CBF compared to donepezil monotherapy [90]. In short, the cognitive-enhancing effects of JWWDT appear to be very associated with increased cholinergic activity in the central nervous system (CNS) as well as improved CBF.

\section{(2) Efficacy and mechanisms of action in AD pathology of each herb in JWWDT}

Efficacy of single herbs of JWWDT is described on Table 4.

\section{a) PN stalk}

Methanol extracts of PN stalks have been reported to protect against neuronal cytotoxicity induced by $A \beta_{25-35}$ in cultured rat cortical neurons by decreasing elevated levels of $\mathrm{Ca}^{2+}$, glutamate release and reactive oxygen species (ROS) generation [91].

\section{b) CU peel}

No studies have examined the effects of the CU peel on $\mathrm{AD}$, however $\mathrm{CU}$ and its major component, nobiletin, have been reported to show neuroprotective effects against $\mathrm{H}_{2} \mathrm{O}_{2}$-induced oxidative stress in HT22 hippocampal neuronal cells via suppressing the phosphorylation of Jun N-terminal kinase, p38 and expression of apoptotic mediators such as bcl-2-like protein 4 (Bax) and caspase-3 [92].

\section{c) GG root}

The administration of aqueous GG root extract has been reported to result in spatial and memory enhancements scopolamine- and diazepam-induced amnesia in rats due to its anti-inflammatory and antioxidative properties [93, 94]. In addition, 2,2',4'-trihydroxychalcone derived from GG has been shown to mitigate memory impairments in an amyloid precursor protein (APP)-presenilin 1 (PS1) double-transgenic mouse model by reducing the production of $A \beta$ through the specific and noncompetitive inhibition of BACE1 [95]. Furthermore, the oral administration of GG aqueous extract significantly reduced AChE activity even more than metrifonate, an irreversible AChE inhibitor, in the brains of Swiss albino mice [96]. 


\section{d) PT root}

Aqueous extracts of PT root have been reported to enhance axonal length and decrease the number of damaged neurons, but did not restore synaptic loss in $\mathrm{A} \beta_{25-35}$-treated rat cortical neurons [97]. Moreover, PT extract inhibited cell death induced by glutamate, $A \beta$ and C-terminal fragment of APP in rat primary cultured neurons. In addition, PT extract improved scopolamineinduced cognitive impairment by dose-dependently and non-competitively inhibiting AChE activity [98].

\section{e) $S N$ root}

Harpagoside, an iridoid glycoside purified from SN root, has been shown to alleviate the cognitive decline of rats induced by bilateral hippocampal injections of aggregated $\mathrm{A} \beta_{1-40}$. In addition, treatment with SN extracts attenuated the decreased number of ChAT-positive neurons and the decreased neurite outgrowth length induced by $A \beta_{1-42}$ in ChAT-positive neurons in cultured primary cortical neurons. These effects appeared to be due to increased BDNF levels and the up-regulation of the MAPK/ phosphoinositide 3-kinase (PI3K) signaling pathway [99].

\section{f) $P G$ root}

Large number of studies have been conducted to examine the effects of PG root on AD. Of the beneficial effects of $P G$ root, reducing $A \beta$ and hyperphosphorylated tau effects are considerable. Administration of PG root extract has been shown to reduce levels of $A \beta_{1-42}$ and phosphorylated tau contents in $\mathrm{AD}$ model rats and promote cognitive function by mediating PI3K/Akt signaling pathway activity [100]. Moreover, ginsenoside $\operatorname{Rg} 1$, a saponin derived from $\mathrm{PG}$, attenuated cognitive impairment in $\mathrm{Tg}$ mAPP mice by decreasing $A \beta_{1-40}, A \beta_{1-42}$ levels in the cerebral cortex and hippocampus. In addition, these modulating effects of APP process was mediated by decreased $\gamma$-secretase activity and increased protein kinase A/cAMP response element-binding (CREB) signaling pathway [101]. Remarkably, the administration of PG powder (4.5 g/day) for 12 weeks to patients with $\mathrm{AD}$ increased the patients' Alzheimer's disease assessment scale and MMSE scores and the scores decreased when PG was withdrawn [102].

\section{g) ZJ fruit}

No studies have reported direct evidence of the effects of ZJ fruit on AD. However, Snakin-Z, a peptide derived from ZJ fruit, has been reported to not only inhibit butyrylcholinesterase $(\mathrm{BChE})$ and $\mathrm{AChE}$ but also to exhibit high antioxidative properties [103].

\section{h) ZJ seed}

Spinosin, a C-glycoside flavonoid derived from ZJ seeds, not only alleviated $A \beta$ oligomer-induced cognitive decline but also inhibited the activation of microglia and ChAT [104]. In addition, spinosin improved memory impairments in mice with scopolamine-induced amnesia and enhanced cognitive performance by increasing adult hippocampal neurogenesis via increased phosphorylation of ERK, CREB and expression of mature BDNF in normal mice $[105,106]$.

\section{i) ZO rhizome}

The effects of $\mathrm{ZO}$ rhizome extracts on $\mathrm{A} \beta$ have been examined in in vitro studies. $\mathrm{ZO}$ extracts increased cell survival, antioxidative activity and decreased $\mathrm{AChE}$ and $\mathrm{BChE}$ levels in $\mathrm{A} \beta$-treated primary adult rat hippocampal cells with high antioxidant activity. Moreover, ZO extracts inhibited $A \beta$ oligomer formation and dissociated the preformed $A \beta$ oligomers [107]. In THP-1 monocytes, $\mathrm{ZO}$ extract has been reported to inhibit lipopolysaccharide and gene expression of $A \beta_{1-42}$-induced proinflammatory cytokines (TNF- $\alpha$, IL-1 $\beta$ and cyclooxygenase-2 (COX2)) and chemokines (MIP-1 $\alpha$ (macrophage inflammatory protein 1-alpha, CCL3), MCP-1 (monocyte chemotactic protein 1, CCL2) and IP-10 (interferon gamma-induced protein 10, CXCL10)) [108]. In addition, aqueous extracts of ZO dose-dependently inhibited AChE activity and lipid peroxidation in the brains of rats [109].

\section{4) Effects of DSS on AD}

DSS (Danggui shaoyao san in Chinese, Dangguijakyaksan in Korean and Tokishakuyakusan in Japan) was first described in a traditional Chinese medical book (Jin gui yao lue) published during the Han dynasty [110]. DSS has been used to treat ovarian dysfunctions, such as amenorrhea, luteal phase deficiency and anovulation [111, 112]. Moreover, previous studies have demonstrated that DSS has beneficial effects on middleaged women with headaches, concomitant depression and sleep disturbances [113-115]. DSS is composed of the following six herbs: Angelica sinensis (AS) Oliv. Diels root, Paeonia lactiflora (PL) Pall. root, Ligusticum chuanxiong (LC) Hort rhizome, Wolfiporia extensa Peck Ginns sclerotium, Atractylodes macrocephala Koidz. rhizome and Alisma orientalis Sam. Juzep. rhizome [116118]. In addition to the beneficial effects of DSS on menopause symptoms, the various effects of DSS in the CNS might be applicable in the treatment of AD.

a) In vivo and in vitro studies of DSS 
In an animal model of dementia, DSS (100 and 200 $\mathrm{mg} / \mathrm{kg}$ ) ameliorated the disruptions in spatial memory induced by scopolamine administration [119]. Treatment of DSS $(300 \mathrm{mg} / \mathrm{kg})$ for 8 days ameliorated cognitive impairment by increasing cell survival in the hippocampus and mRNA levels of the GluR2 in rats with repeated cerebral ischemia [120]. Moreover, DSS (600 $\mathrm{mg} / \mathrm{kg}$ ) treatment for 14 days improved neurobehavioral performance by increasing adult subventricular neurogenesis and microvessel density in a middle cerebral artery occlusion-induced model of ischemic stroke. In addition, DSS activated the vascular endothelial growth factor and promoted endothelial nitric oxide synthase phosphorylation [117]. In addition to studies of the beneficial effects of DSS on cognitive function in $\mathrm{AD}$, studies have examined the underlying mechanisms of these effects. DSS stimulates ChAT activity in the CNS. In ovariectomized mice used as a model of climacteric syndrome, the administration of DSS (ad libitum) inhibited the decrease in ChAT activity in the cerebral cortex and dorsal hippocampus observed at 10 days after ovariectomy and improved the latency times on the PAT [121]. In addition, ChAT activities were increased in the ventral hippocampus by DSS treatment $(500 \mathrm{mg} / \mathrm{kg})$ for 1 month in menopausal rats [122].

However, after early increasing effects on ChAT activity, further treatment of DSS did not change ChAT activity in the hippocampus [122]. Similarly, DSS administration in an ovariectomized model did not change ChAT after early increasing effects on ChAT activity [121]. Even though the specifics of the mechanisms underlying the time-dependent responses to DSS are unclear, these discrepancies suggest that (1) the stimulating effects of DSS on ChAT may be limited and (2) another mechanism may be involved in the beneficial effects on cognitive function. In addition to the stimulating effects of DSS on ChAT, DSS improved cognitive abilities in step-down and MWM tests by increasing estradiol, nitric oxide and glycine levels in the hippocampus and blood plasma in a SAMP8 mouse AD model [116]. In addition, Toriizuka, et al. ${ }^{(121)}$ have shown that DSS increased norepinephrine levels ay 20 days after ovariectomy. Furthermore, 7 days of treatment with DSS $(100 \mu \mathrm{g})$ stimulate the neurite outgrowth of PC12 cells under NGF [69]. Based on the several effects of DSS on the CNS, it can be suggested that DSS is able to improve the symptoms of $\mathrm{AD}$.

\section{b) Clinical trials of DSS}

Several studies examined the therapeutic effects of DSS on patients with $\mathrm{AD}$. One case study reported that DSS treatment improved the scores of patients with AD on the Hasegawa dementia scale and reduced their behavioral symptoms [123]. DSS (7.5 g/day) administration for 8 weeks to patients with $\mathrm{AD}$ and mild cognitive impairment improved CBF and showed a tendency to improve the score of orientation to place in MMSE subscale [124]. In patients with mild cognitive impairments, 8 weeks of DSS treatment increased their MMSE scores and improved regional CBF [125], and 12 weeks of DSS administration improved the scores of Korean-Montreal Cognitive Assessment (K-MOCA) and MMSE as well [126].

\section{(1) Efficacy and mechanisms of action in AD pathology of each herb in DSS}

Efficacy of single herbs of DSS is described on Table 5.

\section{a) AS root}

AS root extract improved $\mathrm{A} \beta$-induced memory impairments in rat models by inhibiting apoptosis, inflammation and nuclear factor $\kappa \mathrm{B}(\mathrm{NF}-\mathrm{\kappa B})$ signaling pathway and the up-regulation of GDNF and BDNF in the hippocampus [127]. Furthermore, AS root extract inhibited $A \beta$-associated neurotoxicity in PC-12 cells and Neuro $2 \mathrm{~A}$ cells via reducing oxidative stress through scavenging free radicals $[128,129]$. The neuroprotective mechanisms underlying the inhibition of $A \beta$ toxicity and tau phosphorylation by AS root treatment were related to regulation of PI3K/Akt/glycogen synthase kinase-3 $\beta$ (GSK-3 $\beta$ ) signaling pathway [130]. Moreover, AS root extract exhibited anti-AChE effects $(65.5 \%)$ in a study screening anti-AChE activities of 29 herbs [131].

\section{b) PL root}

Paeoniflorin, a monoterpene glycoside derived from water-soluble extracts of PL roots, inhibited inflammatory cytokines (TNF- $\alpha$, IL-1 $\beta$ and IL-6) and chemokines (CXCL1 and CCL-2), NF- $\mathrm{KB}$ and VEGF/Flt-1 signaling pathways in $A \beta_{1-42}$-treated rodent microglia [132]. In addition, paeoniflorin mitigated cognitive impairments through the regulation of suppressor of cytokine signaling 2 (SOCS2)/insulin receptor substrate-1 (IRS-1) pathway and activation of Akt and GSK-3 $\beta$ phosphorylation in rats with diabetes [133]. Moreover, lignans isolated from PL showed inhibitory effects on $A \beta_{1-42}$ aggregation via hydrogen or non-hydrogen bond interaction with $A \beta_{1-42}$ [134].

\section{c) LC rhizome}

Tetramethylpyrazine, a major alkaloid derived from LC rhizomes, inhibited proinflammatory mediators such as TNF- $\alpha$, IL- $1 \beta$, MCP-1 and ROS induced by interferon- $\gamma$ and $A \beta_{25-35}$ in primary microglial cells and organotypic hippocampal slice cultures [135]. 
Table 5. The efficacy and therapeutic mechanisms of single herbs constituting DSS on AD.

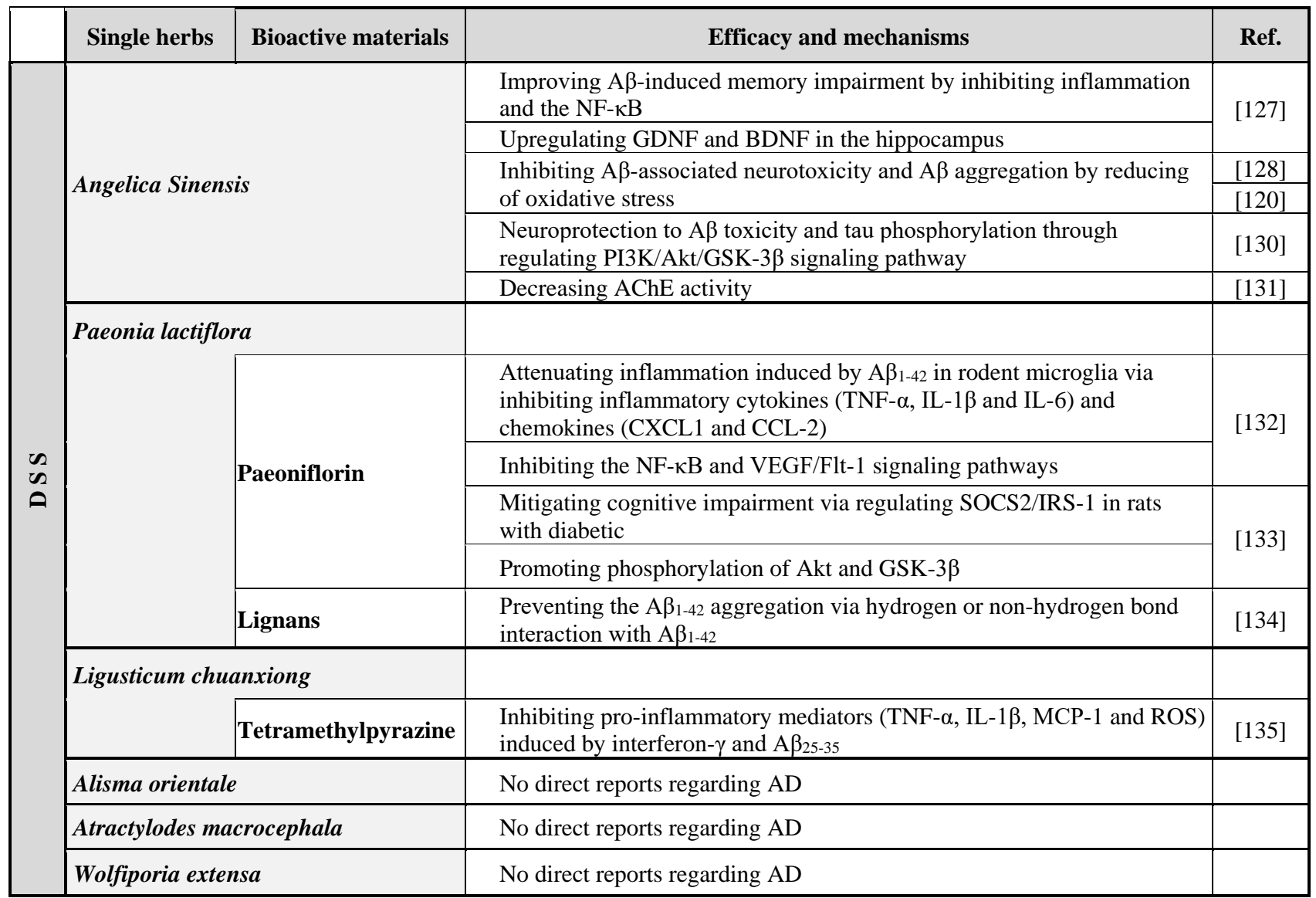

AD: Alzheimer's disease, A $\beta$ : amyloid beta, Akt: protein kinase B (PKB), AChE: acetylcholinesterase BDNF: brain-derived neurotrophic factor, CXCL1: C-X-C motif chemokine ligand 1, CCL-2: C-C motif chemokine ligand 2, Flt-1: functions of the VEGF receptor-1, GDNF: glial cell line-derived

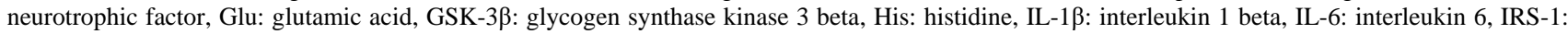
insulin receptor substrate-1, NF- $\mathrm{KB}$ : nuclear factor kappa-light-chain-enhancer of activated B cells, PI3K: phosphoinositide 3-kinase, SOCS2: suppressor of cytokine signaling 2, TNF- $\alpha$ : tumor necrosis factor alpha, VGEF: vascular endothelial growth factor.

\section{Effects of HLJDT on AD}

HLJDT (Huanglian jiedu tang in Chinese, Hwanglyeonhaedoktang in Korean and Orengedokuto in Japan) was first described in a traditional Chinese medical book (Wai tai mi yao) published during the Tang dynasty (752 AD). HLJDT has historically been used to treat excessive body heat, nausea and insomnia [136, 137]. This formula can be used to treat various clinical symptoms, such as gastric mucosal lesions [138, 139], rheumatoid arthritis [140-142], dermatitis [143] and inflammatory diseases $[144,145]$. HLJDT consists of the following 4 herbs: Coptis chinensis (CC) Franch. rhizome, Scutellaria baicalensis (SB) Georgi root, Phellodendron amurense (PA) Rupr. cortex and Gardenia jasminoides (GJ) Ellis fruit [146]. The mechanisms underlying the anti-dementia and cognitive-enhancing effects of HLJDT vary.

\section{a) In vivo and in vitro studies of HLJDT}

A morphologic and histopathologic study have shown that administration of HLJDT decreased damages of hippocampal neurons and formation of senile plaque with increased levels of superoxide dismutase and decreased levels of malondiadehyde [147]. Moreover, berberine, an isoquinoline alkaloid derived from $\mathrm{CC}$, improved cognitive functions by suppressing $A \beta$ accumulation, microglial activation and Akt/GSK3 signaling pathway [148]. In contrast, Durairajan, et al. [149] have reported that HLJDT treatment increases the amyloidogenic metabolism of APP and production of $\mathrm{A} \beta$ in N2aSwedAPP cells, which are used as an in vitro model of AD. They also showed anti-APP and A $\beta$-production effects of a modified formula of HLJDT (removed SB root from original formula). In addition, HLJDT has cognitive enhancing effects in animal models. Similar to the results 
obtained with donepezil administration, coptisine (50 $\mathrm{mg} / \mathrm{kg} /$ day for 1 month), an active constituent of HLJDT also significantly improved the spatial memory impairments by reducing $A \beta_{1-42}$ accumulation and neuronal damage in APP/PS1 transgenic mice [150]. Moreover, effects of HLJDT on cerebral ischemia suggest that HLJDT can be used to treat AD to improve cognitive dysfunction. The oral administration of HLJDT ameliorated the disruption of spatial memory induced by cerebral ischemia in rats and mice [119, 151]. The memory-enhancing effects of HLJDT are mediated by inhibiting the decrement of ACh levels in the cerebral cortex, hippocampus and striatum [151]. More on ACh increasing effects, HLJDT inhibited indoleamine 2,3dioxygenase (IDO), a key enzyme in kynurenine pathway, in vitro [152]. Since over-activation of kynurenine pathway is thought to be involved in $\mathrm{AD}$ pathogenesis, the IDO-inhibiting effects of HLJDT might be one strategy for development $\mathrm{AD}$ treatment.

\section{b) Clinical trials of HLJDT}

A recent clinical trial has reported that 12 weeks of treatment with HLJDT has therapeutic potential in patients with $\mathrm{AD}$ treated with pitavastatin. Patients treated with pitavastatin and HLJDT show significantly lower levels of $A \beta$, phosphorylated tau and inflammatory factors [153]. A case study has reported that supplementary treatment of HLJDT with YGS decreased BPSD in the patient with $\mathrm{AD}$ exhibiting aggressive behaviors [136]. Overall, the results of the clinical and nonclinical studies have suggested that HLJDT has A $\beta$-reducing effects and ameliorates the symptoms of AD.

\section{(1) Efficacy and mechanisms of action in AD pathology of each herb in HLJDT}

Efficacy of single herbs of HLJDT is described on Table 6.

\section{a) CC rhizome}

Coptisine, an active constituent of HLJDT, reduced A $\beta$ formation [150]. Through the $A \beta$-reducing mechanisms of coptisine, the expression of IDO, which is induced by $\mathrm{A} \beta$, was suppressed by HLJDT and its main constituents in vivo and in vitro $[150,152]$. Similar findings have been observed in studies examining the effects of CC rhizome on AD-related pathogenesis. In that study, six alkaloids (berberine, palmatine, jatrorrhizine, coptisine, groenlandicine and epiberberine) isolated from $\mathrm{CC}$ rhizome shown to have inhibitory effect on $\mathrm{AChE}, \mathrm{BChE}$ and two alkaloids (groenlandicine and epiberberine) exhibited inhibitory effects on BACE1. Moreover, jatrorrhizine, groenlandicine and coptisine have antioxidant effects [154].

\section{b) $S B$ root}

Baicalein (5,6,7-trihydroxyflavone), a major flavonoid isolated from SB root, improved learning and spatial memory by activating $\gamma$-aminobutyric acid (GABA) type $A$ receptors and inhibited $A \beta$ production through increasing nonamyloidogenic processing of APP in $\operatorname{Tg} 2576$ mice [155]. An additional notable effect of baicalein was hippocampal neurogenesis promoting effect. Baicalein treatment ameliorated cognitive impairment induced by irradiation via increased hippocampal neurogenesis and up-regulated BDNFpCREB signaling pathway [156]. Another major active component, wogonin, has been reported to improve impaired cognitive function in $3 \times \mathrm{Tg}-\mathrm{AD}$ mice and reduce the levels of $\beta$-secretase, $A \beta$ aggregation and phosphorylated tau in AD cells (Tet-On $\mathrm{A} \beta_{42}$-GFP SHSY5Y neuroblastoma cells). In addition, wogonin also protected against apoptosis and increased mitochondrial membrane potential via suppressing the cleaved poly (ADP-ribose) polymerase (PARP) and expression of Bax [157].

\section{c) PA cortex}

Ethanol extracts of PA cortex have been reported to have protective properties against $A \beta$-induced neurotoxicity via up-regulating the $\mathrm{B}$-cell lymphoma-2 (Bcl-2)/Bax expression ratio and down-regulating the release of cytochrome $\mathrm{c}$ and caspase- 3 expression in PC12 cells [158].

\section{d) GJ fruit}

GJ fruit extracts have reduced $A \beta$-induced cytotoxicity through the reduction of oxidative stress in PC12 cells [159]. Moreover, of the iridoides glucosides isolated from GJ fruit, 6'-O-trans-p-coumaroylgeniposide and 6'-Oacetylgeniposide showed the short-term memoryenhancing effects in an $A \beta$ transgenic drosophila model [160]. In addition, geniposide isolated from GJ inhibited

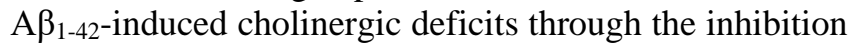
of AChE activity and up-regulation of ChAT in primary hippocampal neurons. Moreover, geniposide inhibited over-activated p38 MAPK, ERK1/2 and receptors for advanced glycation end products (RAGE) which is mediator of $A \beta$ related neurotoxicity, thereby improving cholinergic defects and amyloidosis as well as mitigate cognitive impairments in APP/PS1 mice [161]. 
Table 6. The efficacy and therapeutic mechanisms of single herbs constituting HLJDT on AD.

\begin{tabular}{|c|c|c|c|c|}
\hline & Single herbs & Bioactive materials & Efficacy and mechanisms & Ref. \\
\hline \multirow{20}{*}{$\stackrel{E}{\underline{\theta}}$} & \multicolumn{2}{|c|}{ Coptis chinensis } & & \\
\hline & & \multirow[t]{2}{*}{ Coptisine } & Suppressing IDO expression via reducing $A \beta$ formation & $\begin{array}{r}{[150,} \\
152]\end{array}$ \\
\hline & & & Inhibiting AChE and BChE activity & {$[154]$} \\
\hline & & Berberine & \multirow{3}{*}{ Inhibiting $\mathrm{AChE}$ and $\mathrm{BChE}$ activity } & \multirow{5}{*}{ [154] } \\
\hline & & Palmatine & & \\
\hline & & Jatrorrhizine & & \\
\hline & & Groenlandicine & \multirow{2}{*}{ Inhibiting AChE, BChE and BACE1 activity } & \\
\hline & & Epiberberin & & \\
\hline & \multicolumn{2}{|c|}{ Scutellaria baicalensis } & & \\
\hline & & \multirow{3}{*}{ Baicalein } & $\begin{array}{l}\text { Improving AD-like pathology together with improved cognitive } \\
\text { performance by activation of the GABA type A receptors and the } \\
\alpha \text {-secretase processing of APP. }\end{array}$ & {$[155]$} \\
\hline & & & $\begin{array}{l}\text { Alleviating spatial learning and memory deficits induced by } \\
\text { gamma-ray radiation. }\end{array}$ & \multirow{2}{*}{ [156] } \\
\hline & & & $\begin{array}{l}\text { Stimulating neurogenesis and up-regulating BDNF-pCREB } \\
\text { pathway }\end{array}$ & \\
\hline & & \multirow{3}{*}{ Wogonin } & Improving impaired cognitive function in $3 \times \mathrm{Tg} \mathrm{AD}$ mcie & \multirow{3}{*}{ [157] } \\
\hline & & & $\begin{array}{l}\text { Reducing } \beta \text {-secretase levels, } A \beta \text { aggregation and phosphorylated } \\
\text { tau }\end{array}$ & \\
\hline & & & $\begin{array}{l}\text { Protecting against apoptosis and mitochondrial membrane potential } \\
\text { elevation via suppression of the cleaved PARP and expression of } \\
\text { Bax }\end{array}$ & \\
\hline & \multicolumn{2}{|c|}{ Phellodendron amurense } & $\begin{array}{l}\text { Protecting A } \beta \text {-induced neurotoxicity via upregulating Bcl-2/Bax } \\
\text { ratio and down-regulating cytochrome c and caspase- } 3 \text { expression }\end{array}$ & {$[158]$} \\
\hline & \multicolumn{2}{|c|}{ Gardenia jasminoides } & Reducing $A \beta$-induced cytotoxicity via reduction of oxidative stress & {$[159]$} \\
\hline & & $\begin{array}{l}\text { 6'-O-trans-p- } \\
\text { coumaroylgeniposide } \\
\text { 6'-O- } \\
\text { acetylgeniposide }\end{array}$ & Enhancing short-term memory in $A \beta$ transgenic drosophila model & {$[160]$} \\
\hline & & \multirow[b]{2}{*}{ Geniposide } & Inhibiting the activity of $\mathrm{AChE}$ and increasing the activity of ChAT & \multirow[b]{2}{*}{ [161] } \\
\hline & & & $\begin{array}{l}\text { Mitigating the cognitive impairment in APP/PS1 mice by } \\
\text { inhibition of A } \beta_{1-42-\text { induced cholinergic deficit and amyloidosis via }} \\
\text { inhibition of MAPK }\end{array}$ & \\
\hline
\end{tabular}

\section{Discussion}

$\mathrm{AD}$ is a disease that threatens the quality of life of the patients with the disease as well as their caregivers [162164]. Moreover, the global prevalence of $\mathrm{AD}$ has been persistently increasing and is expected to continue to grow [165]. Therefore, several medicinal interventions have been developed and evaluated. Nonetheless, only a few FDA-approved drugs are in use in most clinical settings. Meanwhile, Oriental herbal medicine, especially herbal formulae, has long been used to treat the symptoms of amnesia and dementias, including $\mathrm{AD}$, in East Asian countries. However, the effects of Oriental herbal medicine on the symptoms of AD have been scientifically investigated for only a few decades. Moreover, TOMs are not widely adopted in Western medicine nor has it been studied by laboratory experiments before the last few decades. Thus, we focused on five herbal formulae that are used frequently in clinical practice.

One of the most notable effects of the formulae is inhibition of $A \beta$ accumulation. As reviewed, several studies regarding formulae and their constituents have reported the inhibitory effects on $A \beta$ aggregation. This might provide an important implication to potential 
treatments for $\mathrm{AD}$. With regard to aforementioned formulae or single herbs, recent studies have revealed beneficial effects of TOMs on AD. One recent study has examined that the combination of herbal formula named GRAPE (mainly consisted with Panax ginseng, Rehmannia glutinosa, Acorus tatarinowii, Polygala tenuifolia, Epimedium brevicornu) with conventional therapy such as donepezil and/or memantine was more effective on cognitive function in $\mathrm{AD}$ patients than conventional therapy alone [166]. Another recent in vivo studies have shown that Bushen Tiansui decoction (consisted with Epimedium brevicornum Maxim, Polygonum multiflorum Thunb, Chinemys reevesii, Fossilia Ossis Mastodi, Polygala, Acorus tatarinowii) and triterpenoid saponins of Xanthoceras sorbifolia Bunge decreased hippocampal damages and cognitive deficits induced by $A \beta$ aggregation [167, 168]. Moreover, an in vitro study reported that extracts from the leaves of Cassia tora Linn. could suppress the A $\beta$ aggregation [169].

However, clinical application of TOMs should be conducted after deliberate consideration of several aspects. In order to apply TOMs in clinical use, TOMs should ensure their safety. Although, TOMs have long been used, there were concerns regarding toxicity induced by heavy metals, pesticides and microorganisms [170]. Another aspect should be considered is that TOMs have established by a unique principle in herbal medicinal prescription as well $[37,171]$. For instance, formulae that prescribed in TOMs is made with several herbs under the consideration of the effects of each active ingredient and principally consisted with major herb (Jun, emperor or monarch), complementary herb (chen, minister), neutralizing herb (zuo, assistant) and delivery herb ( $s h i$, servant or guide) $[172,173]$. Therefore, evaluative studies on TOMs' safety as well as pharmacokinetics and pharmacodynamics of formulae should be conducted for clinical use of TOMs.

The limitation of present review is that this study might not fully ensure the internal and external validity, since this review was not conducted with systematic methodology. Nonetheless of the limitation, reviewing the efficacy and mechanisms of action of standardized TOM formulae commonly used in the clinical practice for patients with cognitive impairments and related symptoms could provide noteworthy implications to potential therapies for AD.

\section{Conclusion}

The major conclusions of this review are the following. First, traditional Oriental herbal medicine is under evaluated despite the extended periods of its use. Recent advances in high-performance liquid chromatography might provide higher peak efficiencies that can be used to more specifically identify each ingredient and component of the formulae. Second, although the inhibitory effects of these herbal formulae on $\mathrm{A} \beta$ accumulation are still controversial, the underlying mechanisms of the inhibitory effects of the herbal formulae (e.g., YGS and HLJDT) and/or bioactive components need to be examined further.

\section{Acknowledgements}

This research was supported by the Basic Science Research Program of the National Research Foundation of Korea (NRF), which is funded by the Ministry of Science, ICT \& Future Planning (NRF2015R1C1A1A01052732), a grant of the Korea Health Technology R\&D Project of the Korea Health Industry Development Institute (KHIDI), which is funded by the Ministry of Health \&Welfare, Republic of Korea (grant number: HI16C0816) and the support of the Cooperative Research Program for Agriculture Science and Technology Development (Project No. PJ01319901) Rural Development Administration, Republic of Korea.

\section{Conflicts of interest}

There are no conflicts of interest.

\section{References}

[1] Goate A, Chartier-Harlin MC, Mullan M, Brown J, Crawford F, Fidani L, et al. (1991). Segregation of a missense mutation in the amyloid precursor protein gene with familial Alzheimer's disease. Nature, 349:704-706.

[2] Braak H, Braak E (1991). Neuropathological stageing of Alzheimer-related changes. Acta Neuropathol, 82:239-259.

[3] Karran E, Mercken M, De Strooper B (2011). The amyloid cascade hypothesis for Alzheimer's disease: an appraisal for the development of therapeutics. Nat Rev Drug Discov, 10:698-712.

[4] Huang Y, Mucke L (2012). Alzheimer mechanisms and therapeutic strategies. Cell, 148:1204-1222.

[5] Gwyther LP (1998). Social issues of the Alzheimer's patient and family. Am J Med, 104:17S-21S; discussion 39S-42S.

[6] Zhu CW, Sano M (2006). Economic considerations in the management of Alzheimer's disease. Clin Interv Aging, 1:143-154.

[7] Riepe MW, Mittendorf T, Forstl H, Frolich L, Haupt M, Leidl R, et al. (2009). Quality of life as an outcome in Alzheimer's disease and other dementias--obstacles and goals. BMC Neurol, 9:47.

[8] McGleenon BM, Dynan KB, Passmore AP (1999). Acetylcholinesterase inhibitors in Alzheimer's disease. British Journal of Clinical Pharmacology, 48:471-480. 
[9] Tabet N (2006). Acetylcholinesterase inhibitors for Alzheimer's disease: anti-inflammatories in acetylcholine clothing! Age Ageing, 35:336-338.

[10] Lukiw WJ (2012). Amyloid beta (A $\beta$ ) peptide modulators and other current treatment strategies for Alzheimer's disease (AD). Expert Opin Emerg Drugs, 17:43-60.

[11] West S, Bhugra P (2015). Emerging drug targets for Abeta and tau in Alzheimer's disease: a systematic review. Br J Clin Pharmacol, 80:221-234.

[12] Kumar A, Singh A, Ekavali (2015). A review on Alzheimer's disease pathophysiology and its management: an update. Pharmacol Rep, 67:195-203.

[13] Cheng X, Zhang L, Lian YJ (2015). Molecular Targets in Alzheimer's Disease: From Pathogenesis to Therapeutics. Biomed Res Int, 2015:760758.

[14] Inestrosa NC, Varela-Nallar L (2014). Wnt signaling in the nervous system and in Alzheimer's disease. J Mol Cell Biol, 6:64-74.

[15] Killick R, Ribe EM, Al-Shawi R, Malik B, Hooper C, Fernandes C, et al. (2014). Clusterin regulates betaamyloid toxicity via Dickkopf-1-driven induction of the wnt-PCP-JNK pathway. Mol Psychiatry, 19:88-98.

[16] Purro SA, Dickins EM, Salinas PC (2012). The secreted Wnt antagonist Dickkopf-1 is required for amyloid beta-mediated synaptic loss. J Neurosci, 32:3492-3498.

[17] Franchi C, Lucca U, Tettamanti M, Riva E, Fortino I, Bortolotti A, et al. (2011). Cholinesterase inhibitor use in Alzheimer's disease: the EPIFARM-Elderly Project. Pharmacoepidemiol Drug Saf, 20:497-505

[18] Sun ZK, Yang HQ, Chen SD (2013). Traditional Chinese medicine: a promising candidate for the treatment of Alzheimer's disease. Transl Neurodegener, 2:6.

[19] Ho YS, So KF, Chang RC (2011). Drug discovery from Chinese medicine against neurodegeneration in Alzheimer's and vascular dementia. Chin Med, 6:15.

[20] Tian J, Shi J, Zhang X, Wang Y (2010). Herbal therapy: a new pathway for the treatment of Alzheimer's disease. Alzheimers Res Ther, 2:30.

[21] Pan SY, Chen SB, Dong HG, Yu ZL, Dong JC, Long ZX, et al. (2011). New perspectives on chinese herbal medicine (zhong-yao) research and development. Evid Based Complement Alternat Med, 2011:403709.

[22] Jang JH, Lee HN, Kim JH, Kim YK (2015). Comparative analysis of herbal formulas in Pharmacopoeia of 4 countries in Northeast Asia. Kor J Herbol, 30:75-83.

[23] Soraoka H, Oniki K, Matsuda K, Ono T, Taharazako K, Uchiyashiki Y, et al. (2016). The Effect of Yokukansan, a Traditional Herbal Preparation Used for the Behavioral and Psychological Symptoms of Dementia, on the Drug-Metabolizing Enzyme Activities in Healthy Male Volunteers. Bio Pharm Bull, 39:14681474.

[24] Iwasaki K, Kobayashi S, Chimura Y, Taguchi M, Inoue $\mathrm{K}$, Cho S, et al. (2004). A randomized, double-blind, placebo-controlled clinical trial of the Chinese herbal medicine "ba wei di huang wan" in the treatment of dementia. J Am Geriatr Soc, 52:1518-1521.
[25] Howes MJ, Houghton PJ (2012). Ethnobotanical treatment strategies against Alzheimer's disease. Curr Alzheimer Res, 9:67-85.

[26] Watanabe Y, Zhang XQ, Liu JS, Guo Z, Ohnishi M, Shibuya T (1995). Protection of glutamate induced neuronal damages in cultured cerebella granule cells by Chinese herbal medicine, Toki-shakuyaku-san and its comprised six medicinal herbs. Journal of Traditional Medicines, 12:93-101.

[27] Sun LM, Zhu BJ, Cao HT, Zhang XY, Zhang QC, Xin GZ, et al. (2018). Explore the effects of Huang-LianJie-Du-Tang on Alzheimer's disease by UPLCQTOF/MS-based plasma metabolomics study. J Pharm Biomed Anal, 151:75-83.

[28] May BH, Lu C, Lu Y, Zhang AL, Xue CC (2013). Chinese herbs for memory disorders: a review and systematic analysis of classical herbal literature. J Acupunct Meridian Stud, 6:2-11.

[29] Gao J, Inagaki Y, Li X, Kokudo N, Tang W (2013). Research progress on natural products from traditional Chinese medicine in treatment of Alzheimer's disease. Drug Discov Ther, 7:46-57.

[30] Cheng HY, Cheng DQ (2009). Progress in research on acupuncture treatment of senile dementia. J Tradit Chin Med, 29:224-233.

[31] Ho Y-S, So K-F, Chang RC-C (2011). Drug discovery from Chinese medicine against neurodegeneration in Alzheimer's and vascular dementia. Chinese Medicine, 6:15.

[32] May BH, Lit M, Xue CCL, Yang AWH, Zhang AL, Owens MD, et al. (2009). Herbal medicine for dementia: a systematic review. Phytotherapy Research, 23:447-459.

[33] Dos Santos-Neto LL, de Vilhena Toledo MA, Medeiros-Souza P, de Souza GA (2006). The use of herbal medicine in Alzheimer's disease-a systematic review. Evid Based Complement Alternat Med, 3:441445.

[34] Howes MR, Fang R, Houghton PJ (2017). Effect of Chinese Herbal Medicine on Alzheimer's Disease. Int Rev Neurobiol, 135:29-56.

[35] Liu Q, Wang SC, Ding K (2017). Research advances in the treatment of Alzheimer's disease with polysaccharides from traditional Chinese medicine. Chin J Nat Med, 15:641-652.

[36] May BH, Feng M, Hyde AJ, Hügel H, Chang SY, Dong $\mathrm{L}$, et al. (2018). Comparisons between traditional medicines and pharmacotherapies for Alzheimerdisease: A systematic review and metaanalysis of cognitive outcomes. Int J Geriatr Psychiatry, 33:449-458.

[37] Che CT, Wang ZJ, Chow MS, Lam CW (2013). Herbherb combination for therapeutic enhancement and advancement: theory, practice and future perspectives. Molecules, 18:5125-5141.

[38] Ikarashi Y, Mizoguchi K (2016). Neuropharmacological efficacy of the traditional Japanese Kampo medicine yokukansan and its active ingredients. Pharmacol Ther, 166:84-95. 
[39] Okamoto H, Iyo M, Ueda K, Han C, Hirasaki Y, Namiki $\mathrm{T}$ (2014). Yokukan-san: a review of the evidence for use of this Kampo herbal formula in dementia and psychiatric conditions. Neuropsychiatr Dis Treat, 10:1727-1742.

[40] Lin Z, Zhu D, Yan Y, Yu B, Wang Q, Shen P, et al. (2011). An Antioxidant Phytotherapy to Rescue Neuronal Oxidative Stress. eCAM, 2011:519517.

[41] Ueki T, Mizoguchi K, Yamaguchi T, Nishi A, Ikarashi Y, Hattori T, et al. (2015). Yokukansan Increases 5HT1A Receptors in the Prefrontal Cortex and Enhances 5-HT1A Receptor Agonist-Induced Behavioral Responses in Socially Isolated Mice. Evid Based Complement Alternat Med, 2015:726471.

[42] Iwasaki K, Satoh-Nakagawa T, Maruyama M, Monma Y, Nemoto M, Tomita N, et al. (2005). A randomized, observer-blind, controlled trial of the traditional Chinese medicine Yi-Gan San for improvement of behavioral and psychological symptoms and activities of daily living in dementia patients. J Clin Psychiatry, 66:248-252.

[43] Tabuchi $M$, Yamaguchi $T$, Iizuka S, Imamura $\mathrm{S}$, Ikarashi Y, Kase Y (2009). Ameliorative effects of yokukansan, a traditional Japanese medicine, on learning and non-cognitive disturbances in the Tg2576 mouse model of Alzheimer's disease. J Ethnopharmacol, 122:157-162.

[44] Fujiwara H, Iwasaki K, Furukawa K, Seki T, He M, Maruyama M, et al. (2006). Uncaria rhynchophylla, a Chinese medicinal herb, has potent antiaggregation effects on Alzheimer's beta-amyloid proteins. J Neurosci Res, 84:427-433.

[45] Fujiwara H, Takayama S, Iwasaki K, Tabuchi M, Yamaguchi T, Sekiguchi K, et al. (2011). Yokukansan, a traditional Japanese medicine, ameliorates memory disturbance and abnormal social interaction with antiaggregation effect of cerebral amyloid beta proteins in amyloid precursor protein transgenic mice. Neuroscience, 180:305-313.

[46] Uchida N, Takasaki K, Sakata Y, Nogami A, Oishi H, Watanabe T, et al. (2013). Cholinergic involvement and synaptic dynamin 1 expression in Yokukansanmediated improvement of spatial memory in a rat model of early Alzheimer's disease. Phytother Res, 27:966972.

[47] Kawakami Z, Ikarashi Y, Kase Y (2011). Isoliquiritigenin is a novel NMDA receptor antagonist in kampo medicine yokukansan. Cell Mol Neurobiol, 31:1203-1212.

[48] Mizukami K, Asada T, Kinoshita T, Tanaka K, Sonohara K, Nakai R, et al. (2009). A randomized cross-over study of a traditional Japanese medicine (kampo), yokukansan, in the treatment of the behavioural and psychological symptoms of dementia. Int J Neuropsychopharmacol, 12:191-199.

[49] Monji A, Takita M, Samejima T, Takaishi T, Hashimoto K, Matsunaga H, et al. (2009). Effect of yokukansan on the behavioral and psychological symptoms of dementia in elderly patients with
Alzheimer's disease. Prog Neuropsychopharmacol Biol Psychiatry, 33:308-311.

[50] Okahara K, Ishida Y, Hayashi Y, Inoue T, Tsuruta K, Takeuchi K, et al. (2010). Effects of Yokukansan on behavioral and psychological symptoms of dementia in regular treatment for Alzheimer's disease. Prog Neuropsychopharmacol Biol Psychiatry, 34:532-536.

[51] Liao JF, Jan YM, Huang SY, Wang HH, Yu LL, Chen CF (1995). Evaluation with receptor binding assay on the water extracts of ten CNS-active Chinese herbal drugs. Proc Natl Sci Counc Repub China B, 19:151158.

[52] Egashira N, Iwasaki K, Ishibashi A, Hayakawa K, Okuno R, Abe M, et al. (2008). Repeated administration of Yokukansan inhibits DOI-induced head-twitch response and decreases expression of 5hydroxytryptamine (5-HT)2A receptors in the prefrontal cortex. Prog Neuropsychopharmacol Biol Psychiatry, 32:1516-1520.

[53] Terawaki K, Ikarashi Y, Sekiguchi K, Nakai Y, Kase Y (2010). Partial agonistic effect of yokukansan on human recombinant serotonin $1 \mathrm{~A}$ receptors expressed in the membranes of Chinese hamster ovary cells. J Ethnopharmacol, 127:306-312.

[54] Koonrungsesomboon N, Na-Bangchang K, Karbwang J (2014). Therapeutic potential and pharmacological activities of Atractylodes lancea (Thunb.) DC. Asian Pac J Trop Med, 7:421-428.

[55] Gella A, Durany N (2009). Oxidative stress in Alzheimer disease. Cell Adhesion \& Migration, 3:8893.

[56] Obara Y, Aoki T, Kusano M, Ohizumi Y (2002). Betaeudesmol induces neurite outgrowth in rat pheochromocytoma cells accompanied by an activation of mitogen-activated protein kinase. J Pharmacol Exp Ther, 301:803-811.

[57] Nogami-Hara A, Nagao M, Takasaki K, Egashira N, Fujikawa R, Kubota K, et al. (2018). The Japanese Angelica acutiloba root and yokukansan increase hippocampal acetylcholine level, prevent apoptosis and improve memory in a rat model of repeated cerebral ischemia. J Ethnopharmacol, 214:190-196.

[58] Hatip-Al-Khatib I, Egashira N, Mishima K, Iwasaki K, Iwasaki K, Kurauchi K, et al. (2004). Determination of the effectiveness of components of the herbal medicine Toki-Shakuyaku-San and fractions of Angelica acutiloba in improving the scopolamine-induced impairment of rat's spatial cognition in eight-armed radial maze test. J Pharmacol Sci, 96:33-41.

[59] Liu J, Mori A (1992). Antioxidant and free radical scavenging activities of Gastrodia elata Bl. and Uncaria rhynchophylla (Miq.) Jacks. Neuropharmacology, 31:1287-1298.

[60] Hsieh CL, Tang NY, Chiang SY, Hsieh CT, Lin JG (1999). Anticonvulsive and free radical scavenging actions of two herbs, Uncaria rhynchophylla (MIQ) Jack and Gastrodia elata Bl., in kainic acid-treated rats. Life Sci, 65:2071-2082.

[61] Xian YF, Lin ZX, Zhao M, Mao QQ, Ip SP, Che CT (2011). Uncaria rhynchophylla ameliorates cognitive 
deficits induced by D-galactose in mice. Planta Med, 77:1977-1983.

[62] Xian YF, Lin ZX, Mao QQ, Hu Z, Zhao M, Che CT, et al. (2012). Bioassay-Guided Isolation of Neuroprotective Compounds from Uncaria rhynchophylla against Beta-Amyloid-Induced Neurotoxicity. Evid Based Complement Alternat Med, 2012:802625.

[63] Yang ZD, Duan DZ, Du J, Yang MJ, Li S, Yao XJ (2012). Geissoschizine methyl ether, a corynantheantype indole alkaloid from Uncaria rhynchophylla as a potential acetylcholinesterase inhibitor. Nat Prod Res, 26:22-28.

[64] Yoshioka T, Murakami K, Ido K, Hanaki M, Yamaguchi K, Midorikawa S, et al. (2016). Semisynthesis and Structure-Activity Studies of Uncarinic Acid C Isolated from Uncaria rhynchophylla as a Specific Inhibitor of the Nucleation Phase in Amyloid beta42 Aggregation. J Nat Prod, 79:25212529.

[65] Lee TH, Park SH, You MH, Lim JH, Min SH, Kim BM (2016). A potential therapeutic effect of Saikosaponin $\mathrm{C}$ as a novel dual-target anti-Alzheimer agent. J Neurochem, 136:1232-1245.

[66] Ahn J, Um M, Choi W, Kim S, Ha T (2006). Protective effects of Glycyrrhiza uralensis Fisch. on the cognitive deficits caused by beta-amyloid peptide 25-35 in young mice. Biogerontology, 7:239-247.

[67] Link P, Wetterauer B, Fu Y, Wink M (2015). Extracts of Glycyrrhiza uralensis and isoliquiritigenin counteract amyloid-beta toxicity in Caenorhabditis elegans. Planta Med, 81:357-362.

[68] Yamabe N, Yokozawa T, Kim HY, Cho EJ (2005). Protective effect of Hachimi-jio-gan against renal failure in a subtotal nephrectomy rat model. J Pharm Pharmacol, 57:1637-1644.

[69] Kano Y, Hiragami F, Kawamura K, Takaguchi S, Kimata Y, Poffenberger CK, et al. (2001). Establishment of a drug-hypersensitive pc12 mutant clone deficient in nerve growth factor-induced neurite outgrowth. Tissue culture research communications, 20:145-153.

[70] Hirokawa S, Nose M, Ishige A, Amagaya S, Oyama T, Ogihara Y (1996). Effect of Hachimi-jio-gan on scopolamine-induced memory impairment and on acetylcholine content in rat brain. J Ethnopharmacol, 50:77-84

[71] Hirokawa S, Nose M, Ishige A, Amagaya S, Ogihara Y (1994). Effect of hachimijiogan, an oriental herbal medicinal mixture, on experimental amnesia in mice. Biol Pharm Bull, 17:1182-1186.

[72] Iwasaki K, Kobayashi Si, Chimura Y, Taguchi M, Inoue K, Akiba T, et al. (2004). Effects of the Chinese herbal medicine 'Ba Wei Di Huang Wan' in the treatment of dementia: A SPECT cerebral blood flow examination and a randomized, double-blind, placebocontrolled clinical trial for cognitive function and ADL. Geriatrics \& Gerontology International, 4:S124-S128.

[73] Wang Z, Liu Q, Zhang R, Liu S, Xia Z, Hu Y (2009). Catalpol ameliorates beta amyloid-induced degeneration of cholinergic neurons by elevating brainderived neurotrophic factors. Neuroscience, 163:13631372.

[74] Huang JZ, Wu J, Xiang S, Sheng S, Jiang Y, Yang Z, et al. (2016). Catalpol preserves neural function and attenuates the pathology of Alzheimer's disease in mice. Mol Med Rep, 13:491-496.

[75] Lee B, Shim I, Lee H, Hahm DH (2011). Rehmannia glutinosa ameliorates scopolamine-induced learning and memory impairment in rats. J Microbiol Biotechnol, 21:874-883.

[76] Yu H, Oh-Hashi K, Tanaka T, Sai A, Inoue M, Hirata Y, et al. (2006). Rehmannia glutinosa induces glial cell line-derived neurotrophic factor gene expression in astroglial cells via cPKC and ERK1/2 pathways independently. Pharmacol Res, 54:39-45.

[77] Lee KY, Sung SH, Kim SH, Jang YP, Oh TH, Kim YC (2009). Cognitive-enhancing activity of loganin isolated from Cornus officinalis in scopolamineinduced amnesic mice. Arch Pharm Res, 32:677-683.

[78] Youn K, Jun M (2012). Inhibitory effects of key compounds isolated from Corni fructus on BACE1 Activity. Phytother Res, 26:1714-1718.

[79] Bhakta HK, Park CH, Yokozawa T, Tanaka T, Jung HA, Choi JS (2017). Potential anti-cholinesterase and beta-site amyloid precursor protein cleaving enzyme 1 inhibitory activities of cornuside and gallotannins from Cornus officinalis fruits. Arch Pharm Res, 40:836-853.

[80] Kim KH, Kim MA, Moon E, Kim SY, Choi SZ, Son MW, et al. (2011). Furostanol saponins from the rhizomes of Dioscorea japonica and their effects on NGF induction. Bioorg Med Chem Lett, 21:2075-2078. [81] Fujiwara H, Tabuchi M, Yamaguchi T, Iwasaki K, Furukawa K, Sekiguchi K, et al. (2009). A traditional medicinal herb Paeonia suffruticosa and its active constituent 1,2,3,4,6-penta-O-galloyl-beta-Dglucopyranose have potent anti-aggregation effects on Alzheimer's amyloid beta proteins in vitro and in vivo. J Neurochem, 109:1648-1657.

[82] Zhou J, Zhou L, Hou D, Tang J, Sun J, Bondy SC (2011). Paeonol increases levels of cortical cytochrome oxidase and vascular actin and improves behavior in a rat model of Alzheimer's disease. Brain Res, 1388:141147.

[83] Park S, Kang S, Kim DS, Moon BR (2017). Agrimonia pilosa Ledeb., Cinnamomum cassia Blume, and Lonicera japonica Thunb. protect against cognitive dysfunction and energy and glucose dysregulation by reducing neuroinflammation and hippocampal insulin resistance in beta-amyloid-infused rats. Nutr Neurosci, 20:77-88

[84] Nakagawasai O, Yamadera F, Iwasaki K, Arai H, Taniguchi R, Tan-No K, et al. (2004). Effect of kamiuntan-to on the impairment of learning and memory induced by thiamine-deficient feeding in mice. Neuroscience, 125:233-241.

[85] Oh HK, Park SJ, Bae SG, Kim MJ, Jang JH, Ahn YJ, et al. (2013). Kami-ondam-tang, a traditional herbal prescription, attenuates the prepulse inhibition deficits 
and cognitive impairments induced by MK-801 in mice. J Ethnopharmacol, 146:600-607.

[86] Yabe T, Toriizuka K, Yamada H (1996). Kami-untanto (KUT) improves cholinergic deficits in aged rats. Phytomedicine, 2:253-258.

[87] Yabe T, Iizuka S, Komatsu Y, Yamada H (1997). Enhancements of choline acetyltransferase activity and nerve growth factor secretion by Polygalae radixextract containing active ingredients in Kami-untan-to. Phytomedicine, 4:199-205.

[88] Yabe T, Yamada H (1997). Kami-Untan-To enhances choline acetyltransferase and Nerve growth factor mRNA levels in brain cultured cells. Phytomedicine, 3:361-367.

[89] Arai H, Suzuki T, Sasaki H, Hanawa T, Toriizuka K, Yamada H (2000). A new interventional strategy for Alzheimer's disease by Japanese herbal medicine. Nihon Ronen Igakkai Zasshi, 37:212-215.

[90] Maruyama M, Tomita N, Iwasaki K, Ootsuki M, Matsui T, Nemoto M, et al. (2006). Benefits of combining donepezil plus traditional Japanese herbal medicine on cognition and brain perfusion in Alzheimer's disease: a 12-week observer-blind, donepezil monotherapy controlled trial. J Am Geriatr Soc, 54:869-871.

[91] Ban JY, Cho SO, Kwon SH, Kim JB, Seong NS, Bae KW, et al. (2005). Protection of Amyloid $\beta$ Protein (2535)-induced Neuronal Cell Damage by Methanol Extract of New Stem of Phyllostachys nigra Munro var. henonis Stapf in Cultured Rat Cortical Neuron. Korean J Med Crop Sci, 13:95-102.

[92] Cho HW, Jung SY, Lee GH, Cho JH, Choi IY (2015). Neuroprotective effect of Citrus unshiu immature peel and nobiletin inhibiting hydrogen peroxide-induced oxidative stress in HT22 murine hippocampal neuronal cells. Pharmacogn Mag, 11:S284-289.

[93] Dhingra D, Parle M, Kulkarni SK (2004). Memory enhancing activity of Glycyrrhiza glabra in mice. $\mathbf{J}$ Ethnopharmacol, 91:361-365.

[94] Chakravarthi KK, Avadhani R (2013). Beneficial effect of aqueous root extract of Glycyrrhiza glabra on learning and memory using different behavioral models: An experimental study. J Nat Sci Biol Med, 4:420-425.

[95] Zhu Z, Li C, Wang X, Yang Z, Chen J, Hu L, et al. (2010). 2,2',4'-trihydroxychalcone from Glycyrrhiza glabra as a new specific BACE1 inhibitor efficiently ameliorates memory impairment in mice. J Neurochem, 114:374-385.

[96] Dhingra D, Parle M, Kulkarni SK (2006). Comparative brain cholinesterase-inhibiting activity of Glycyrrhiza glabra, Myristica fragrans, ascorbic acid, and metrifonate in mice. J Med Food, 9:281-283.

[97] Naito R, Tohda C (2006). Characterization of antineurodegenerative effects of Polygala tenuifolia in Abeta(25-35)-treated cortical neurons. Biol Pharm Bull, 29:1892-1896.

[98] Park CH, Choi SH, Koo JW, Seo JH, Kim HS, Jeong $\mathrm{SJ}$, et al. (2002). Novel cognitive improving and neuroprotective activities of Polygala tenuifolia Willdenow extract, BT-11. J Neurosci Res, 70:484-492.
[99] Li J, Ding X, Zhang R, Jiang W, Sun X, Xia Z, et al. (2015). Harpagoside ameliorates the amyloid-betainduced cognitive impairment in rats via up-regulating BDNF expression and MAPK/PI3K pathways. Neuroscience, 303:103-114.

[100] Li H, Kang T, Qi B, Kong L, Jiao Y, Cao Y, et al. (2016). Neuroprotective effects of ginseng protein on $\mathrm{PI} 3 \mathrm{~K} /$ Akt signaling pathway in the hippocampus of Dgalactose/AlCl3 inducing rats model of Alzheimer's disease. J Ethnopharmacol, 179:162-169.

[101] Fang F, Chen X, Huang T, Lue LF, Luddy JS, Yan SS (2012). Multi-faced neuroprotective effects of Ginsenoside Rg1 in an Alzheimer mouse model. Biochim Biophys Acta, 1822:286-292.

[102] Lee ST, Chu K, Sim JY, Heo JH, Kim M (2008). Panax ginseng enhances cognitive performance in Alzheimer disease. Alzheimer Dis Assoc Disord, 22:222-226.

[103] Zare-Zardini H, Tolueinia B, Hashemi A, Ebrahimi L, Fesahat F (2013). Antioxidant and cholinesterase inhibitory activity of a new peptide from Ziziphus jujuba fruits. Am J Alzheimers Dis Other Demen, 28:702-709.

[104] Ko SY, Lee HE, Park SJ, Jeon SJ, Kim B, Gao Q, et al. (2015). Spinosin, a C-Glucosylflavone, from Zizyphus jujuba var. spinosa Ameliorates Abeta1-42 OligomerInduced Memory Impairment in Mice. Biomol Ther (Seoul), 23:156-164.

[105] Jung IH, Lee HE, Park SJ, Ahn YJ, Kwon G, Woo H, et al. (2014). Ameliorating effect of spinosin, a Cglycoside flavonoid, on scopolamine-induced memory impairment in mice. Pharmacol Biochem Behav, 120:88-94.

[106] Lee Y, Jeon SJ, Lee HE, Jung IH, Jo YW, Lee S, et al. (2016). Spinosin, a C-glycoside flavonoid, enhances cognitive performance and adult hippocampal neurogenesis in mice. Pharmacol Biochem Behav, 145:9-16.

[107] Mathew M, Subramanian S (2014). In vitro evaluation of anti-Alzheimer effects of dry ginger (Zingiber officinale Roscoe) extract. Indian J Exp Biol, 52:606612.

[108] Grzanna R, Phan P, Polotsky A, Lindmark L, Frondoza CG (2004). Ginger extract inhibits beta-amyloid peptide-induced cytokine and chemokine expression in cultured THP-1 monocytes. J Altern Complement Med, 10:1009-1013.

[109] Oboh G, Ademiluyi AO, Akinyemi AJ (2012). Inhibition of acetylcholinesterase activities and some pro-oxidant induced lipid peroxidation in rat brain by two varieties of ginger (Zingiber officinale). Exp Toxicol Pathol, 64:315-319.

[110] Qian YF, Wang H, Yao WB, Gao XD (2008). Aqueous extract of the Chinese medicine, Danggui-ShaoyaoSan, inhibits apoptosis in hydrogen peroxide-induced PC12 cells by preventing cytochrome c release and inactivating of caspase cascade. Cell Biol Int, 32:304311.

[111] Koyama T, Hagino N, Cothron AW, Saito M (1988). Effect of toki-shakuyaku-san on ovulation induced by 
human menopausal gonadotropin in rats. Am J Chin Med, 16:169-172.

[112] Lee HW, Jun JH, Kil KJ, Ko BS, Lee CH, Lee MS (2016). Herbal medicine (Danggui Shaoyao San) for treating primary dysmenorrhea: A systematic review and meta-analysis of randomized controlled trials. Maturitas, 85:19-26.

[113] Terauchi M, Hiramitsu S, Akiyoshi M, Owa Y, Kato K, Obayashi S, et al. (2014). Effects of the kampo formula tokishakuyakusan on headaches and concomitant depression in middle-aged women. Evid Based Complement Alternat Med, 2014:593560.

[114] Terauchi M, Kubota T. 2016. Menopausal Symptoms and the Kampo Medicine: Tokishakuyakusan, Kamishoyosan, and Keishibukuryogan. In Herbal Medicines: New Horizons. A. Inui, editor. New York, NY: Springer New York. 81-96.

[115] Terauchi M, Hiramitsu S, Akiyoshi M, Owa Y, Kato K, Obayashi S, et al. (2011). Effects of three Kampo formulae: Tokishakuyakusan (TJ-23), Kamishoyosan (TJ-24), and Keishibukuryogan (TJ-25) on Japanese peri- and postmenopausal women with sleep disturbances. Arch Gynecol Obstet, 284:913-921.

[116] Huang Y, Hu ZY, Yuan H, Shu L, Liu G, Qiao SY, et al. (2014). Danggui-Shaoyao-San Improves Learning and Memory in Female SAMP8 via Modulation of Estradiol. Evid Based Complement Alternat Med, 2014:327294.

[117] Ren C, Wang B, Li N, Jin K, Ji X (2015). Herbal Formula Danggui-Shaoyao-San Promotes Neurogenesis and Angiogenesis in Rat Following Middle Cerebral Artery Occlusion. Aging Dis, 6:245253.

[118] Fu X, Wang Q, Wang Z, Kuang H, Jiang P (2016). Danggui-Shaoyao-San: New Hope for Alzheimer's Disease. Aging and Disease, 7:502-513.

[119] Fujiwara M, Iwasaki K (1993). Toki-Shakuyaku-San and Oren-Gedoku-To improve the disruption of spatial cognition induced by cerebral ischaemia and central cholinergic dysfunction in rats. Phytother Res, 7:S60S62.

[120] Pu F, Mishima K, Egashira N, Akiyoshi Y, Liu AX, Sano K, et al. (2005). Post-ischemic treatment with toki-shakuyaku-san (tang-gui-shao-yao-san) prevents the impairment of spatial memory induced by repeated cerebral ischemia in rats. Am J Chin Med, 33:475-489.

[121] Toriizuka K, Hou P, Yabe T, Iijima K, Hanawa T, Cyong JC (2000). Effects of Kampo medicine, Tokishakuyaku-san (Tang-Kuei-Shao-Yao-San), on choline acetyltransferase activity and norepinephrine contents in brain regions, and mitogenic activity of splenic lymphocytes in ovariectomized mice. J Ethnopharmacol, 71:133-143.

[122] Sakamoto S, Hagino N, Toriizuka K (1994). Effect of Toki-Shakuyaku-San (TJ-23) on the activity of choline acetyltransferase in the brain of menopausal rats. Phytother Res, 8:208-211.

[123] Harada H (1997). The Effects of Toki-Shyakuyaku-San on Alzheimer's Disease. Kampo Medicine, 47:861-867.
[124] Matsuoka T, Narumoto J, Shibata K, Okamura A, Taniguchi S, Kitabayashi Y, et al. (2012). Effect of toki-shakuyaku-san on regional cerebral blood flow in patients with mild cognitive impairment and Alzheimer's disease. Evid Based Complement Alternat Med, 2012:245091.

[125] Kitabayashi Y, Shibata K, Nakamae T, Narumoto J, Fukui K (2007). Effect of traditional Japanese herbal medicine toki-shakuyaku-san for mild cognitive impairment: SPECT study. Psychiatry Clin Neurosci, 61:447-448.

[126] Kim KH, Go HY, Lee JA, Choi J, Park S, Lee MS, et al. (2016). The Effect of Dangguijagyag-san on Mild Cognitive Impairment. J Altern Complement Med, 22:509-514.

[127] Duan MH, Wang LN, Jiang YH, Pei YY, Guan DD, Qiu ZD (2016). Angelica sinensis reduced Abeta-induced memory impairment in rats. J Drug Target, 24:340-347.

[128] Huang SH, Lin CM, Chiang BH (2008). Protective effects of Angelica sinensis extract on amyloid betapeptide-induced neurotoxicity. Phytomedicine, 15:710721.

[129] Ho CC, Kumaran A, Hwang LS (2009). Bio-assay guided isolation and identification of anti-Alzheimer active compounds from the root of Angelica sinensis. Food Chem, 114:246-252.

[130] Zhang Z, Zhao R, Qi J, Wen S, Tang Y, Wang D (2011). Inhibition of glycogen synthase kinase-3beta by Angelica sinensis extract decreases beta-amyloidinduced neurotoxicity and tau phosphorylation in cultured cortical neurons. J Neurosci Res, 89:437-447.

[131] Park CH, Kim SH, Choi W, Lee YJ, Kim JS, Kang SS, et al. (1996). Novel anticholinesterase and antiamnesic activities of dehydroevodiamine, a constituent of Evodia rutaecarpa. Planta Med, 62:405-409.

[132] Liu H, Wang J, Wang J, Wang P, Xue Y (2015). Paeoniflorin attenuates Abeta1-42-induced inflammation and chemotaxis of microglia in vitro and inhibits NF-kappaB- and VEGF/Flt-1 signaling pathways. Brain Res, 1618:149-158.

[133] Sun X, Li S, Xu L, Wang H, Ma Z, Fu Q, et al. (2017). Paeoniflorin ameliorates cognitive dysfunction via regulating SOCS2/IRS-1 pathway in diabetic rats. Physiol Behav, 174:162-169.

[134] Liu X, Yang MH, Wang XB, Xie SS, Li ZR, Kim DH, et al. (2015). Lignans from the root of Paeonia lactiflora and their anti-beta-amyloid aggregation activities. Fitoterapia, 103:136-142.

[135] Kim M, Kim SO, Lee M, Lee JH, Jung WS, Moon SK, et al. (2014). Tetramethylpyrazine, a natural alkaloid, attenuates pro-inflammatory mediators induced by amyloid beta and interferon-gamma in rat brain microglia. Eur J Pharmacol, 740:504-511.

[136] Okamoto H, Chino A, Hirasaki Y, Ueda K, Iyo M, Namiki T (2013). Orengedoku-to augmentation in cases showing partial response to yokukan-san treatment: a case report and literature review of the evidence for use of these Kampo herbal formulae. Neuropsychiatr Dis Treat, 9:151-155. 
[137] Yang Q, Gao L, Tao M, Chen Z, Yang X, Cao Y (2016). Transcriptomics Analysis of Candida albicans Treated with Huanglian Jiedu Decoction Using RNA-seq. Evid Based Complement Alternat Med, 2016:3198249.

[138] Ohta Y, Kobayashi T, Nishida K, Nagata M, Ishiguro I (1999). Therapeutic effect of Oren-gedoku-to extract on stress-induced acute gastric mucosal lesions in rats. Phytother Res, 13:588-592.

[139] Ohta Y, Kobayashi T, Nishida K, Sasaki E, Ishiguro I (1999). Preventive effect of Oren-gedoku-to (Huanglian-Jie-Du-Tang) extract on the development of stress-induced acute gastric mucosal lesions in rats. J Ethnopharmacol, 67:377-384.

[140] Yue R, Zhao L, Hu Y, Jiang P, Wang S, Xiang L, et al. (2013). Metabolomic study of collagen-induced arthritis in rats and the interventional effects of huanglian-jie-du-tang, a traditional chinese medicine. Evid Based Complement Alternat Med, 2013:439690.

[141] Hu Y, Hu Z, Wang S, Dong X, Xiao C, Jiang M, et al. (2013). Protective effects of Huang-Lian-Jie-Du-Tang and its component group on collagen-induced arthritis in rats. J Ethnopharmacol, 150:1137-1144.

[142] Fang H, Wang Y, Yang T, Ga Y, Zhang Y, Liu R, et al. (2013). Bioinformatics analysis for the antirheumatic effects of huang-lian-jie-du-tang from a network perspective. Evid Based Complement Alternat Med, 2013:245357.

[143] Saikawa M, Oguchi K, Nakayama S (2006). Effects of kampo medicines used in contact dermatitis and atopic dermatitis on delayed-type hypersensitivity in mice. Journal of The Showa Medical Association, 66:360369.

[144] Zeng H, Liu X, Dou S, Xu W, Li N, Liu X, et al. (2009). Huang-Lian-Jie-Du-Tang exerts anti-inflammatory effects in rats through inhibition of nitric oxide production and eicosanoid biosynthesis via the lipoxygenase pathway. J Pharm Pharmacol, 61:16991707.

[145] Zeng H, Dou S, Zhao J, Fan S, Yuan X, Zhu S, et al. (2011). The inhibitory activities of the components of Huang-Lian-Jie-Du-Tang (HLJDT) on eicosanoid generation via lipoxygenase pathway. J Ethnopharmacol, 135:561-568.

[146] Lu T, Song J, Huang F, Deng Y, Xie L, Wang G, et al. (2007). Comparative pharmacokinetics of baicalin after oral administration of pure baicalin, Radix scutellariae extract and Huang-Lian-Jie-Du-Tang to rats. J Ethnopharmacol, 110:412-418.

[147] Qiu X, Chen GH, Wang T (2011). [Effects of huanglian jiedu decoction on free radicals metabolism and pathomorphism of the hippocampus in App/PS1 double transgenic mice]. Zhongguo Zhong Xi Yi Jie He Za Zhi, 31:1379-1382.

[148] Durairajan SS, Liu LF, Lu JH, Chen LL, Yuan Q, Chung SK, et al. (2012). Berberine ameliorates betaamyloid pathology, gliosis, and cognitive impairment in an Alzheimer's disease transgenic mouse model. Neurobiol Aging, 33:2903-2919.

[149] Durairajan SS, Huang YY, Yuen PY, Chen LL, Kwok KY, Liu LF, et al. (2014). Effects of Huanglian-Jie-Du-
Tang and its modified formula on the modulation of amyloid-beta precursor protein processing in Alzheimer's disease models. PLoS One, 9:e92954.

[150] Yu D, Tao BB, Yang YY, Du LS, Yang SS, He XJ, et al. (2015). The IDO inhibitor coptisine ameliorates cognitive impairment in a mouse model of Alzheimer's disease. J Alzheimers Dis, 43:291-302.

[151] Xu J, Murakami Y, Matsumoto K, Tohda M, Watanabe H, Zhang S, et al. (2000). Protective effect of Orengedoku-to (Huang-Lian-Jie-Du-Tang) against impairment of learning and memory induced by transient cerebral ischemia in mice. J Ethnopharmacol, 73:405-413.

[152] Yu CJ, Zheng MF, Kuang CX, Huang WD, Yang Q (2010). Oren-gedoku-to and its constituents with therapeutic potential in Alzheimer's disease inhibit indoleamine 2, 3-dioxygenase activity in vitro. J Alzheimers Dis, 22:257-266.

[153] Chen H-L, Guan F (2016). Effect of Huanglian Jiedu Decoction on pitavastatin treatment of Alzheimer's disease. Journal of Hainan Medical College, 22:71-74.

[154] Jung HA, Min BS, Yokozawa T, Lee JH, Kim YS, Choi JS (2009). Anti-Alzheimer and antioxidant activities of Coptidis Rhizoma alkaloids. Biol Pharm Bull, 32:14331438.

[155] Zhang SQ, Obregon D, Ehrhart J, Deng J, Tian J, Hou $\mathrm{H}$, et al. (2013). Baicalein reduces beta-amyloid and promotes nonamyloidogenic amyloid precursor protein processing in an Alzheimer's disease transgenic mouse model. J Neurosci Res, 91:1239-1246.

[156] Oh SB, Park HR, Jang YJ, Choi SY, Son TG, Lee J (2013). Baicalein attenuates impaired hippocampal neurogenesis and the neurocognitive deficits induced by gamma-ray radiation. Br J Pharmacol, 168:421-431.

[157] Huang DS, Yu YC, Wu CH, Lin JY (2017). Protective Effects of Wogonin against Alzheimer's Disease by Inhibition of Amyloidogenic Pathway. Evid Based Complement Alternat Med, 2017:3545169.

[158] Xian YF, Lin ZX, Ip SP, Su ZR, Chen JN, Lai XP (2013). Comparison the neuropreotective effect of Cortex Phellodendri chinensis and Cortex Phellodendri amurensis against beta-amyloid-induced neurotoxicity in PC12 cells. Phytomedicine, 20:187-193.

[159] Choi SJ, Kim MJ, Heo HJ, Hong B, Cho HY, Kim YJ, et al. (2007). Ameliorating effect of Gardenia jasminoides extract on amyloid beta peptide-induced neuronal cell deficit. Mol Cells, 24:113-118.

[160] Yu Y, Xie ZL, Gao H, Ma WW, Dai Y, Wang Y, et al. (2009). Bioactive iridoid glucosides from the fruit of Gardenia jasminoides. J Nat Prod, 72:1459-1464.

[161] Zhao C, Zhang H, Li H, Lv C, Liu X, Li Z, et al. (2017). Geniposide ameliorates cognitive deficits by attenuating the cholinergic defect and amyloidosis in middle-aged Alzheimer model mice. Neuropharmacology, 116:18-29.

[162] Logsdon RG, Gibbons LE, McCurry SM, Teri L (1999). Quality of life in Alzheimer's disease: Patient and caregiver reports. J Men Health Aging, 5:21-32.

[163] Zucchella C, Bartolo M, Bernini S, Picascia M, Sinforiani E (2015). Quality of life in Alzheimer 
disease: a comparison of patients' and caregivers' points of view. Alzheimer Dis Assoc Disord, 29:50-54.

[164] Kahle-Wrobleski K, Ye W, Henley D, Hake AM, Siemers E, Chen YF, et al. (2017). Assessing quality of life in Alzheimer's disease: Implications for clinical trials. Alzheimers Dement (Amst), 6:82-90.

[165] Prince M, Bryce R, Albanese E, Wimo A, Ribeiro W, Ferri CP (2013). The global prevalence of dementia: a systematic review and metaanalysis. Alzheimers Dement, 9:63-75.e62.

[166] Shi J, Ni J, Lu T, Zhang X, Wei M, Li T, et al. (2017). Adding Chinese herbal medicine to conventional therapy brings cognitive benefits to patients with Alzheimer's disease: a retrospective analysis. BMC Complement Altern Med, 17:533.

[167] Hui S, Yang Y, Peng WJ, Sheng CX, Gong W, Chen S, et al. (2017). Protective effects of Bushen Tiansui decoction on hippocampal synapses in a rat model of Alzheimer's disease. Neural Regen Res, 12:1680-1686.

[168] Ji XF, Chi TY, Liu P, Li LY, Xu JK, Xu Q, et al. (2017). The total triterpenoid saponins of Xanthoceras sorbifolia improve learning and memory impairments through against oxidative stress and synaptic damage. Phytomedicine, 25:15-24.

[169] Chethana KR, Senol FS, Orhan IE, Anilakumar KR, Keri RS (2017). Cassia tora Linn.: A boon to Alzheimer's disease for its anti-amyloidogenic and cholinergic activities. Phytomedicine, 33:43-52.

[170] Liu SH, Chuang WC, Lam W, Jiang Z, Cheng YC (2015). Safety surveillance of traditional Chinese medicine: current and future. Drug Saf, 38:117-128.

[171] Lim HJ, Kim JH, Cho SY, Park SD, Kim YK (2015). Implication of Korean Medicine Principles in Herbal Medicinal Preparations on Pharmaceutical Affairs Act. Herbal Formula Science, 23:1-14.

[172] Kim HU, Ryu JY, Lee JO, Lee SY (2015). A systems approach to traditional oriental medicine. Nat Biotechnol, 33:264-268.

[173] $\mathrm{Xu} \mathrm{Y} \mathrm{(2015).} \mathrm{'Less} \mathrm{is} \mathrm{more'} \mathrm{in} \mathrm{the} \mathrm{Chinese} \mathrm{context.}$ Shanghai Arch Psychiatry, 27:371-373. 